\title{
Does EU Cohesion Policy Work? Theory and Evidence *
}

\author{
Davide Fiaschi ${ }^{\dagger}$ Andrea Mario Lavezzi ${ }^{\ddagger}$ and Angela Parenti ${ }^{\S}$
}

\author{
September 7, 2017
}

\begin{abstract}
This paper evaluates the effectiveness of European Cohesion Policy in the regions of 12 EU countries in the period 1991-2008, on the basis of a spatial growth model which allows for the identification of both direct and indirect effects of EU funds on GDP per worker growth. We find that "Objective 1" funds are characterized by strong spatial externalities and a positive and concave effect on the growth of GDP per worker, which reaches a peak at the ratio funds/GDP of approximately $3 \%$ and becomes non-significant after $4 \%$. "Objective 2" and "Cohesion" funds have non-significant effects, while all the other funds exert a positive and significant effect, but their size is very limited. EU Cohesion Policy, moreover, appears to have increased its effectiveness over time. In the period 2000-2006 Objective 1 funds are estimated to have a median multiplier equal to 1.52 , and to have added $0.37 \%$ to the GDP per worker growth. Overall, in the period 1991-2008 funds are estimated to have added $1.4 \%$ to the median annual growth, and to have reduced regional disparities of 8 basis points in terms of the Gini index.
\end{abstract}

Keywords: European regional disparities, European regional policy, spatial spillovers, Structural and Cohesion Funds, spatial panel model.

JEL: C21; E60; O52; R11; R12

\footnotetext{
${ }^{*}$ Previous versions of this paper circulated with the title: "Productivity Growth across European Regions: the Impact of Structural and Cohesion Funds".

${ }^{\dagger}$ Department of Economics and Management, University of Pisa, e-mail: davide.fiaschi@unipi.it, phone +39.050 .2216208 , fax: +39.050.2216384 (corresponding author)

$\ddagger$ Department of Law, University of Palermo, e-mail: mario.lavezzi@unipa.it

$\S$ IMT Lucca, e-mail: angela.parenti@imtlucca.it
} 


\section{INTRODUCTION}

In this paper we assess the impact of European Union (EU) Cohesion Policy on regional productivity growth in the period 1991-2008. In particular, we propose a spatial growth model that allows for the identification of two types of effects of EU funds: a direct effect on growth of the recipient region, and an indirect effect stemming from spatial spillovers from neighbouring regions.

The EU allocates a relevant part of its budget (about EUR 213 billion at 1999 prices over the period 2000-2006) to promote social and economic cohesion among the regions of the member states. The overall goals of EU policy are to promote the competitiveness of European regions (Articles 130(f)-130(p), Single European Act, 1987) and, at the same time, to reduce: "disparities between the levels of development of various regions, and the backwardness of the less-favoured regions" (Article 130(a), Single European Act, 1987). In 2017, given the recent enlargement of EU to 28 countries, and in the light of the debate on how: "fiscal policies should support the economic recovery through public investment" (Draghi, 2016), EU policy is all the more important in the EU agenda.

Previous research tried to answer several questions on EU Cohesion Policy, from the most general on its effectiveness in increasing EU regional growth and reducing disparities (see in particular the pioneering contribution of Boldrin and Canova, 2001), to more specific questions on the effect of different types of funds (such as those targeted to the poorest regions, see, e.g., Dall'Erba and Le Gallo, 2008). Subsequently, more specific issues have been addressed. For example, Dall'Erba et al. (2009) analyse the opportunity to geographically concentrate funding in order to exploit possible spatial externalities, while Becker et al. (2012) suggest to allocate funds more equally among regions if funds have decreasing marginal effects. Farole et al. (2011) discuss the potential trade-off between growth and the reduction of regional disparities in the allocation of funds, while Rodríguez-Pose and Novak (2013) focus on the effective benefits of the changes in the implementation and management of EU Cohesion Policy over different programming periods. Finally, Becker et al. (2013) identify the regional characteristics enhancing the effectiveness of funds (see Barca, 2009 and Pieńkowski and Berkowitz, 2015 for exhaustive reviews 
of the literature).

The major focus of this paper, i.e. the effectiveness of EU funds, however, still represents a matter of controversy (Maynou et al., 2016). Funds' effectiveness is mostly, but not exclusively, evaluated by econometric analyses of growth and convergence across European regions, and several studies found positive growth effects of EU Cohesion policy (see, e.g., De la Fuente and Vives, 1995, Cappelen et al., 2003, Rodríguez-Pose and Fratesi, 2004, Beugelsdijk and Eijffinger, 2005, Ederveen et al., 2006, and Checherita et al., 2009). In particular, several econometric estimates find a positive effect of funds targeted to "Objective 1" regions, i.e. regions having a per capita GDP lower than $75 \%$ of EU average (see, e.g., Ramajo et al., 2008, Mohl and Hagen, 2010, Becker and von Ehrlich, 2010; Becker et al., 2012, 2013, Pellegrini et al., 2013, and De Dominicis, 2014). More specifically, Gagliardi and Percoco (2017) find that the highest effect on growth is experienced by rural Objective 1 regions that are closer to urban centres; Ferrara et al. (2016) find that Objective 1 funds had positive effects on infrastructure development (proxied by road accessibility), and, especially, on innovation activities (proxied by patents applications); Giua (2017) finds that Regional Policy had a positive impact on Italian regional employment; and, finally, Di Cataldo (2017) highlights the negative impact of Brexit (with the subsequent loss of EU funding) on UK regions. Other works, on the contrary, find non-significant or even negative effects (Boldrin and Canova, 2001, Dall'Erba and Le Gallo, 2008, and Dall'Erba et al., 2009).

Other approaches to study the effectiveness of funds include Brandsma et al. (2015), who propose to calibrate a dynamic spatial equilibrium to study the impact of Cohesion Policy; Fortuna et al. (2016) who, adopting a Computational General Equilibrium approach, find by simulations that the elimination of EU funds in the Portuguese region of Azores would have caused a significant drop in its levels of GDP and consumption; and, finally, Medeiros (2017) who, adopting the Territorial Impact Analysis approach, finds the highest impact of the funds in Spain in the "socio-economic cohesion" dimension, and the lowest in the "morphologic polycentricity" dimension.

These studies, however, differ in the type of funds analysed, sample size, program- 
ming periods and methodology (see Pieńkowski and Berkowitz, 2015). In addition, much work on the effect of EU funding neglects spatial effects among EU regions (see, e.g., De la Fuente and Vives, 1995, Cappelen et al., 2003, Rodríguez-Pose and Fratesi, 2004, Beugelsdijk and Eijffinger, 2005, Ederveen et al., 2006, Checherita et al., 2009, Becker et al., 2012, 2013, and Pellegrini et al., 2013), even though several works found significant evidence of their presence (see, e.g., Dall'Erba and Le Gallo, 2008, Dall'Erba et al., 2009, Mohl and Hagen, 2010, Le Gallo et al., 2011, and De Dominicis, 2014). Tests for spatial externalities of funds (Le Gallo et al., 2011) and their possible nonlinear effects (Becker et al., 2012) and are even rarer in the literature.

In this paper we propose to evaluate the impact of funds by a spatial Solovian growth model. Funds affect regional production both in an unmediated way, as public expenditure in Barro (1990), and in a mediated way, by generating spatial total factor productivity (TFP) externalities, in the spirit of Bottazzi and Peri (2003) and Ertur and Koch (2007). The theoretical model allows for the derivation of an econometric model belonging to the class of Spatial Durbin Models (see Anselin, 1988).

We then estimate the econometric model on a sample of 175 regions from EU12 for three programming periods (1989-1993, 1994-1999 and 2000-2006), controlling for endogeneity of funds, time effects, and unobserved regional characteristics. Our results suggest that the effect of funds is characterized by strong spatial externalities, and that not all types of funds stimulate regional growth. In particular, the effect on the growth of GDP per worker of "Objective 1" funds is positive and concave, reaching a peak at the ratio funds/GDP of approximately $3 \%$ and becoming non-significant after 4\%. "Objective 2" and "Cohesion" funds have non-significant effects, while all the other funds exert a positive and significant effect, but their impact is very small given their limited size. In addition, we find that EU Cohesion Policy appears to increase its effectiveness over time. Focusing on the most recent programming period considered in the analysis (2000-2006), we estimate a median multiplier equal to 1.52 for Objective 1 funds, which added $0.38 \%$ to the median regional annual growth of GDP per worker. Overall, EU Cohesion Policy in the period 1991-2008 is estimated to have added $1.4 \%$ to the median annual growth, 
and to have reduced regional disparities by 8 basis points in terms of the Gini index.

We contribute to the existing literature in several respects. First, the proposed theoretical spatial growth model allows for a transparent derivation of the different channels (i.e. direct and indirect) through which funds affect regional growth, and provides a guide for their identification in the empirical analysis, i.e. it helps to assess: "how long-lasting these effects [of funds] are [...] and ... the precise mechanisms underlying the effects on growth" (Neumark and Simpson, 2015, p. 1275). Differently, most of the literature on Cohesion Policy, including the contributions considering spatial externalities, takes a data-driven approach in which covariates are inserted in the econometric analyses without reference to a fully-specified model, introducing risks of misspecification and omitted variable problems (Pieńkowski and Berkowitz, 2015).

Second, in line with our theoretical model, we depart from the most of literature and study the effects of funding on growth of regional GDP per worker, instead of GDP per capita. We argue that GDP per worker is the correct measure to evaluate the capacity of EU Cohesion Policy to enhance regional competitiveness (Annoni and Kozovska, 2010) and favour backward regions.

Third, we build an harmonized dataset on EU Cohesion Policy for the period 19892006 disaggregated by different types of funds at NUTS 2 level, plugging a gap in the literature discussed, e.g., in Pieńkowski and Berkowitz (2015). This allows to exploit panel data techniques to control for regional unobservable characteristics. In particular, the econometric model includes both regional and time fixed effects, and spatially lagged variables, and is estimated by fixed-effect spatial panel techniques, filling a lacuna in the literature highlighted by Mohl and Hagen (2010).

Fourth, we discuss both theoretically and empirically the crucial role of spatial externalities of funds in the analysis of the effects of EU Cohesion Policy, whose importance in the evaluation of place-based policies is discussed by Neumark and Simpson (2015). However, so far, but with other methodologies, only Becker and von Ehrlich (2010), Le Gallo et al. (2011) and Gagliardi and Percoco (2017) have analysed this phenomenon. In particular, Becker and von Ehrlich (2010) use a regression discontinuity design to identify 
the effect on an Objective-1 region of the funds received by other Objective- 1 regions within some distance (150 or $200 \mathrm{~km}$ ). Le Gallo et al. (2011) use the SALE model suggested by Pace and LeSage (2004) to estimate a specific effect of funds on each region. However, they consider a smaller sample and a shorter time period (145 regions in the period 1989-1999), and do not disaggregate funds by objectives. Finally, Gagliardi and Percoco (2017) highlight that the impact of Objective-1 funds displays a spatial pattern determined by the territorial characteristics of regions (i.e. their degree of urbanization and distance from main urban agglomerates).

Fifth, we contribute to the debate on the possibility for EU Cohesion Policy to "maximize overall growth while also achieving continuous convergence in outcomes and productivity across Europes regions" (Farole et al., 2011). Specifically, our analysis suggests that Cohesion Policy in 1989-2006 was effective for both enhancing growth and reducing regional disparities.

Finally, we introduce a new methodology to select the best specification of a spatial weights matrix based on the value of AICc (see Anderson, 2007), which represents an alternative to the Bayesian approach proposed by LeSage and Pace (2009). We find that the best spatial weights matrix is based on a combination of geographical and technological proximity (proxied by the geographical distances among regions and the (di)similarity of the regional output compositions respectively). This finding supports the idea that regional spatial externalities should also include knowledge spillovers (Boschma, 2005 and Aghion and Jaravel, 2015), an aspect generally neglected in the literature on regional growth (an exception is Basile et al., 2012).

The paper is organized as follows. Section 2 summarizes the main features of EU Cohesion Policy; Section 3 describes our dataset; Section 4 proposes a spatial growth model with EU funds; Section 5 derives the econometric model and presents the results of the empirical analysis; Section 6 contains concluding remarks and discusses the policy implications of our findings. 


\section{THE EU COHESION POLICY}

EU Cohesion Policy aims at promoting regions' competitiveness and at reducing the economic and social disparities among the regions of the member states. The allocation of most of funds is based on the definition of a number of "objectives" (originally from 1 to 6), among which the most important is the relative backwardness of a region, and of "Community Initiatives Programmes". In particular, in the period 1994-2006 a large portion of the funds went to "Objective 1" regions, i.e. regions with a per capita GDP lower than 75\% of EU average. Moreover, since the programming period 1994-1999 the Cohesion Fund is allocated to less-developed states, i.e. states with a per capita GDP below $90 \%$ of EU average, to support environmental and transport infrastructure projects. In the programming period 2000-2006 the number of objectives and initiatives was reduced to "Objective 1", "Objective 2", and to Community Initiatives: INTERREG III (interregional cooperation) and URBAN II (sustainable development of urban areas) (see Molle, 2007 and Pellegrini et al., 2013 for more details). Neumark and Simpson (2015) discuss EU Cohesion Policy as a place-based policy, which can be: "rationalized by various hypotheses in urban and labor economics, such as agglomeration economies and spatial mismatch." Since 2006 the classification of regions into Objectives has been discontinued, and current terminology refers to "least developed" regions for those originally defined "Objective 1" regions (see https://europa.eu/european-union/topics/regional-policy_en), while the former "Objective 2" regions are not precisely identified. However, in the rest of paper we maintain the old terminology to facilitate the comparison with the literature.

In particular, three features of EU Cohesion Policy appear particularly important for our analysis. First, from our reading of the allocation criteria, not all types of funds are unambiguously direct to stimulate regional GDP per worker, in particular in backward regions, in contrast with the stated goals of favouring competitiveness and reducing disparities among European regions. Boldrin and Canova (2001, p. 211) argue that the overall EU policy appears: "to serve a redistributional purpose", and not to favour growth and convergence. In particular, only Objective 1 funds and Cohesion Funds are explicitly targeted to the poorest regions to favour their catching-up. On the contrary, Objective 2 
funds, aiming at supporting declining industries, and Objective 5 funds, supporting the agricultural and fishing sectors, may actually slow down GDP per worker growth. In fact, these types of funding are likely to interfere with the process of structural change, in which the resources from mature sectors, i.e. the agricultural and fishing sectors, are gradually reallocated to more innovative and productive sectors (Dall'Erba et al., 2009, p. 93, make a similar remark). These funds therefore should be considered more income support than stimuli to GDP per worker growth. The same remark applies to the Cohesion Funds: on the one hand the development of, e.g., waste disposal plants does not seem directly linked to productivity growth; on the other, the development of interregional (and international) transport networks may have a positive or negative effect on regional productivity depending on the direction that the subsequent agglomeration of economic activity follows (see Ottaviano and Thisse, 2004 and Rodríguez-Pose and Fratesi, 2004). Therefore, the sign of the impact of some type of funds on the growth rate of GDP per worker is a priori ambiguous.

A second remark regards the considerable effort of the European Commission to refine and improve the EU Cohesion Policy over different programming periods (see RodríguezPose and Novak, 2013). The major changes happened between the second and third programming periods included in our analysis. In particular, the concentration in fewer objectives in the third programming period was associated to higher geographical concentration in the funds' allocation and to greater targeting of resources to the poorest regions (see Rodríguez-Pose and Novak, 2013 and Section 3 below). Moreover, in the third programming period there was a shift in the types of investments from infrastructures to the promotion of competitiveness, job creation, education and training (see Molle, 2007). Finally, European Commission (2001b) discusses the important institutional changes of the third programming period, among which the involvement in the elaboration of the policy of several institutional actors, in addition to Commission and Member States governments, and the greater attention to monitoring and evaluating of the actual results of interventions. In this regard, Rodríguez-Pose and Novak (2013) find evidence of a "learning process" in the implementation of EU Cohesion Policy. 
A final remark regards the key presence of spatial externalities in the implementation of the EU Cohesion Policy (see Neumark and Simpson, 2015, p. 1225). In fact, spatial externalities are likely to characterize investments in infrastructures, largely decided and implemented by transnational cooperation partnerships, but also to affect other types of investments, largely funded in the most recent programming periods, such as those aiming at supporting the accumulation of "knowledge" (e.g. investment in education and workforce's training). By their nature, this type of investments can generate significant knowledge spillovers (see Breschi and Lissoni, 2001 for a critical review of this phenomenon). For example, financing of road infrastructures affects production in the region where the road infrastructures are built, but also has an impact on the same region caused by the road infrastructures built in its neighbouring regions (see Neumark and Simpson, 2015, p. 1268). Alternatively, a rise in productivity in a region due to, e.g., new technologies generated by R\&D investments, or improvements in workers' skills caused by a training program, may diffuse to its neighbours. Hence the presence of spatial externalities implies that EU funds should be expected to have two types of effect on regional GDP per worker: an unmediated effect, i.e. a primary effect on GDP per worker growth due to the funds allocated to the region (i.e. funds work as an input for local production), and a mediated effect of the EU funds allocated to other regions, caused by the presence of spatial externalities. More importantly, we should observe a multiplicative effect of funds on GDP per worker of regions, whose identification will require a specific procedure (see Section 4 for further details) We will take into account these remarks in the elaboration of the theoretical model in Section 4 and in the empirical analysis of Section 5 .

\section{THE STRUCTURAL AND COHESION FUNDS DATASET}

We use data on Structural and Cohesion Funds covering three programming periods: 1989-1993 (Period I), 1994-1999 (Period II), and 2000-2006 (Period III) for 175 regions of twelve EU countries, with the exclusion of regions belonging to the former East Germany, 
one Dutch region (Flevoland), and two Spanish regions (Ceuta and Melilla and Canarias). ${ }^{1}$

All funds are expressed in 2000 constant prices.

We discard the period 1975-1988 because the allocation was not driven by specific Objectives while, as discussed in Section 2, a correct analysis on the effectiveness of Cohesion Policy requires to separately consider the different types of funds. This also led us to consider payments for the period 2000-2006 and commitments for the periods 1989-1993 and 1994-1999 as a proxy for the actual use of funds in a region. ${ }^{2}$ Payments clearly represent a more precise measurement of the use of funds, but focusing on this measure would imply to limit the analysis only to Period III (2000-2006), losing the crucial advantages of panel data analysis (i.e. the possibility to control for regional unobservable heterogeneity and to analyse how the effectiveness of Cohesion Policy changed over time). As general remark, the use of commitments in periods I and II could induce a downward bias in the estimated effect of funds, and a measurement error problem (see Hagen and Mohl, 2008). In Section 5.2 we will deal with both issues.

We consider European regions at NUTS 2 level but, since only $57 \%$ of total funds in Periods I and II are directly allocated to individual regions, we adopted the following criteria to approximate the actual amount of funds received by a region (see also Rodríguez-Pose and Fratesi, 2004, p. 111 and Mohl and Hagen, 2010, p. 356):

- if the fund is jointly allocated to a group of regions, we reassign it to individual NUTS 2 regions in an amount inversely proportional to their per capita GDP in the initial year of the programming period ( $4 \%$ of total funds in our dataset);

- if the fund is allocated to a country, but it is possible to identify the eligible regions (e. g. Objective 1), then it is reassigned to all the eligible regions (e. g. Objective 1

\footnotetext{
${ }^{1}$ The exclusion of the regions of former Easter Germany and Flevoland is due to missing data in the instrumental variables used to control for the endogeneity of funds, while Ceuta and Melilla and Canarias has no neighbours for many of spatial weights matrix used in the analysis (see Section 5 for more details). Data are collected from different publications of the European Commission: European Commission (1995) and European Commission (1997) (Period I); European Commission (1997) and European Commission (2000) (Period II); SWECO International (2008) (Period III). See Appendix C for the list of regions.

${ }^{2}$ For the period 1994-1999, the joint availability of data on commitments and payments at NUTS 2 level (but without any disaggregation by types of funds) allows to calculate that, on average, about $75 \%$ of commitments were effectively used, and that heterogeneity in the use of funds across regions was relatively low. For the period 1989-1993, data are available only at country level, with an average use of about $80 \%$ (Parenti, 2009).
} 
regions) in an amount inversely proportional to their per capita GDP in the initial year of the programming period ( $26 \%$ of total funds);

- if the fund is allocated at country level, but it is not possible to identify the eligible regions (e. g. the Cohesion Funds), then we reassign it to all the NUTS 2 regions of the country in an amount inversely proportional to their per capita GDP in the initial year of the programming periods (13\% of total funds).

We chose to reassign the funds proportionally to per capita GDP since this is the main criterion used for the allocation of most of the funds (e.g. Objective 1 and Cohesion Funds). The results presented below remain significantly unaffected if we reassign funds to individual regions with respect their GDP per worker (results available upon request).

\subsection{Descriptive statistics}

The measure of the funds used in the analysis will be the ratio between the annual mean amount of funds given to a region in a programming period and the GDP level of the region in the first year of programming period. Data on regional GDP are from Cambridge Econometrics (2010) (codes and data are available at the authors' websites). The use of the first year for GDP aims at avoiding the reverse causation effect from GDP growth to funds' intensity. This variable will be denoted SCF, and will proxy for the intensity of funding on the production side of the economy. ${ }^{3}$

Table 1 shows the evolution of SCF in the three programming periods and the share of the funds allocated to the regions in our sample with respect to the total amount of funding. The overall intensity of funding with respect to total EU GDP (i.e. of the GDP of the 12 countries considered in the analysis), is almost equal in Periods I and III, and reaches a peak of $0.33 \%$ in Period II. There are some fluctuations in the average and median regional level of SCF and in its standard deviation, but these differences did not result statistically significant from a bootstrap test (results available upon request).

\footnotetext{
${ }^{3}$ With "intensity of funding" we are using the jargon of controlled experiments as in Becker et al. (2012), to be interpreted as the (annual) intensity of the treatment received by regions through the Cohesion Policy.
} 


\begin{tabular}{l|cc|c|ccc}
\hline \hline $\begin{array}{l}\text { Programming } \\
\text { Period }\end{array}$ & $\begin{array}{c}\text { \% SCF } \\
\text { to our sample }\end{array}$ & $\begin{array}{c}\text { \% OB1 funds } \\
\text { to our sample }\end{array}$ & $\begin{array}{c}\text { Share of total funds } \\
\text { on 12-EU GDP }\end{array}$ & $\begin{array}{c}\text { Average } \\
\text { SCF }\end{array}$ & $\begin{array}{c}\text { Median } \\
\text { SCF }\end{array}$ & $\begin{array}{c}\text { St. Dev. } \\
\text { of SCF }\end{array}$ \\
\hline Period I & 88.93 & 92.10 & 0.0021 & 0.0057 & 0.0019 & 0.0091 \\
Period II & 75.98 & 69.70 & 0.0033 & 0.0057 & 0.0016 & 0.0088 \\
Period III & 73.52 & 72.69 & 0.0021 & 0.0057 & 0.0016 & 0.0109 \\
\hline \hline
\end{tabular}

Table 1: Descriptive statistics on Structural and Cohesion Funds in the three programming periods Period I (1989-1992), Period II (1994-1999), and Period III (2000-2006) for the sample of 175 regions of Appendix C.

Table 2 reports the shares of the different types of funds across the programming periods. It shows that Objective 1 attracted the largest share of funds in all periods with an average share of approximately 65\%, followed by Cohesion and Objective 2 funds, whose shares peaked in Period III to $16.7 \%$ and $16.8 \%$ of total funds, respectively. ${ }^{4}$

\begin{tabular}{l|ccc}
\hline \hline Objective & Period I (1989-1993) & Period II (1994-1999) & Period III (2000-2006) \\
\hline 1 & 67.3 & 59.7 & 63.7 \\
2 & 9.2 & 6.2 & 16.7 \\
3 & - & 8.0 & - \\
4 & - & 1.3 & - \\
3 \& 4 & 10.4 & - & - \\
5 a (Agriculture) & 5.4 & 3.2 & - \\
5a (Fishery) & 0.9 & 0.4 & - \\
5b & 3.8 & 4.2 & - \\
PIM & 0.4 & - & 0.5 \\
2 Initiative & - & 3.3 & 2.4 \\
Other Initiatives & - & 1.9 & 16.8 \\
Cohesion & 2.6 & 11.8 & 100 \\
\hline Total & 100 & 100 & \\
\hline \hline
\end{tabular}

Table $\overline{\overline{2:} \text { Percentage of commitments of funds according to Objectives for the sample of } 175 \text { regions of }}$ Appendix C. "PIM": regional program in Period I for regions outside Objective 1; "2 Initiative": regional initiatives similar to Objective 2 for period III (Adapt, Employment, Rechard, Resider, Retex, Konver, $S M E s)$, "Other Initiatives": other initiatives in Period II (Leader, Regis, Urban, Pesca, Peace)

Table 3, finally, presents the distribution of the funds among the less productive regions in our sample (i.e. with GDP per worker below 75\%). ${ }^{5}$ The first row, indicating the overall share of funds received by this group of regions, shows that their share is increasing over time but it is never higher than $50 \%$. The less productive regions, however, receive a high and increasing share of Objective 1 funds, in line with the principle of allocating these funds to the poorest regions. Yet this share, on average, never reaches $60 \%$ of total funds. As noted by Becker and von Ehrlich (2010) with respect to Objective 1 funds, some

\footnotetext{
${ }^{4}$ Although the Cohesion Fund was created with the 1993 reform, it began to operate in 1993 under a temporary regulation. Thus, a part of the total funds was allocated as Cohesion Fund also in Period I.

${ }^{5}$ This threshold is chosen to mimic the threshold identifying Objective 1 regions. The correlation between per capita GDP and per worker GDP in our sample is very high $(0.79,0.84$ and 0.85 in Periods I, II, and III respectively).
} 
"poor" regions might not receive funding, while some "rich" regions might receive them, because of some of the rules governing the allocation of funds across different programming periods, such as the ones on the so-called "phasing-out" support, provided to Objective 1 regions after they passed the $75 \%$ threshold. The main insight from Table 3 is that, notwithstanding the aim of favouring catching-up and competitiveness gains of the most disadvantaged regions, a sizeable amount of EU funding is not actually directed to them.

\begin{tabular}{l|ccc}
\hline \hline & Period I (1989-1993) & Period II (1994-1999) & Period III (2000-2006) \\
\hline All Objectives & 37.5 & 44.7 & 47.5 \\
Objective 1 & 52.3 & 58.0 & 58.1 \\
Objective 2 & 0.0 & 0.0 & 1.6 \\
Objective 3 \& 4 5 & 3.5 & 1.6 & - \\
Objective 6 \& Other Initiatives & 0.0 & 26.2 & 45.4 \\
Cohesion & 60.9 & 83.4 & 61.4 \\
\hline \hline
\end{tabular}

Table 3: Percentage of total funds and of different types of funds given to regions with GDP per worker below $75 \%$ of sample mean for the sample of 175 regions of Appendix C.

To sum up, with respect to our sample, the most salient features of EU Cohesion Policy are: i) the resources devoted by the European Union to the Cohesion Policy as ratio to EU GDP have increased from Period I (1989-1993) to Period II (1994-1999), to come back to the same level in Period III (2000-2006); ii) by far, most of the funds are devoted to reach Objective 1; iii) the share of Cohesion Funds has remarkably increased over time, reaching a considerable size in Period II; iv) Objective 2 funding is also substantial, relative to the other Objectives different from 1 and Cohesion funds; v) a non-negligible share of EU funding is allocated to "not-so-poor" regions.

\section{A Spatial Growth Model with Structural and Co- hesion Funds}

In this section we present a modified Solovian growth model which encompasses both the mediated and unmediated impacts of EU funds and allows to evaluate their relative importance. As regards the unmediated impact, we follow the insights of the Barro (1990)'s model, in which public expenditure appears as an input in production, providing a flow of services that affects the marginal product of private factors of production. In 
particular, assume that the GDP of region $i$ at time $t$ is given by:

$$
Y_{i t}=G\left(f_{i}\right) K_{i t}^{\alpha}\left(A_{i t} L_{i t}\right)^{1-\alpha}
$$

with $\alpha \in(0,1)$, where $f_{i}, K_{i t}, L_{i t}$, and $A_{i t}$ respectively denote the ratio of EU funds received by region $i$ to regional GDP (assumed to be constant over time $t$ ), the capital stock, the employment level, and the total factor productivity (TFP) of region $i$ at time t. For the sake of simplicity we ignore the role of human capital in production (but we will nonetheless control for its effects in the empirical analysis).

The shape of $G\left(f_{i}\right)$ determines the unmediated effect of EU funds on $Y_{i t}$, which can be either to enhance the returns of private factors (like in Barro, 1990), or to decrease the overall efficiency of an economy by affecting the efficient reallocation of resources across sectors (as discussed in Section 2). ${ }^{6}$ To maintain maximum flexibility we only assume that $G(0)=1$ (i.e. funds are not essential for production), and $G\left(f_{i}\right)>0$ if $f_{i}>0$ (production is always positive).

As regards the mediated impact of EU funds, we assume that spatial externalities of EU Cohesion Policy operate through $A_{i t}$. In particular, following Bottazzi and Peri (2003) and Ertur and Koch (2007), assume that $A_{i t}$ can be expressed as:

$$
A_{i t}=\psi\left(f_{i}\right) \Omega_{i t} \prod_{j=1, j \neq i}^{N} A_{j t}^{\theta w_{i j}}
$$

where $N$ is the number of regions and $\Omega_{i t}$ measures the region-specific TFP that does not depend neither on the EU funds nor on the TFP of neighbouring regions, denoted by $A_{j t}$. The parameter $\theta \in[0,1)$ measures the strength of the spatial externalities, while $w_{i j} \in \mathbf{W}$, weights the spatial externalities from regions $j$ to region $i$ (see Anselin, 2003). All terms $w_{i j}$ are non-stochastic, finite, and such that $w_{i j} \in[0,1], w_{i j}=0$ if $i=j$, and $\sum_{j \neq i}^{N} w_{i j}=1$ for $i=1, \ldots, N$. To maintain the maximum flexibility we only assume that $\psi(0)=1$ (i.e. funds are not essential for TFP), and $\psi\left(f_{i}\right)>0$ for $f_{i}>0$ (TFP is always

\footnotetext{
${ }^{6}$ The scalar $f_{i}$ could be substituted by a vector of different types of funds received by region $i$ (Objective 1 , Objective 2, etc.), allowing each type to have a different effect on production. This aspect will be considered in the empirical analysis of Section 5 .
} 
positive).

Assume that region-specific TFP is growing at the exogenous rate $\mu$, i.e. $\Omega_{i t}=\Omega_{i 0} e^{\mu t}$, where $\Omega_{i 0}$ is the initial level, ${ }^{7}$ then (see Appendix A for the proof):

$$
A_{i t}=\prod_{j=1}^{N}\left[\psi\left(f_{j}\right) \Omega_{j 0}\right]^{\nu_{i j}} e^{\frac{\mu t}{1-\theta}}=A_{i 0} e^{\gamma^{A} t}
$$

where $A_{i 0}$ is the initial level of TFP of region $i$, which also includes the impact of spatial externalities; $\nu_{i j}=\sum_{r=1}^{\infty} \theta^{r} w_{i j}{ }^{(r)}$ is the parameter measuring the total spatial externalities that region $i$ receives from region $j ; \nu_{i i}=1+\sum_{r=1}^{\infty} \theta^{r} w_{i i}{ }^{(r)}$ is the parameter quantifying the total spatial externalities that region $i$ receives from itself, which is equal to 1 (i.e. there are no spatial externalities from a region to itself) either for $\theta=0$ or under the assumption of $w_{i j}=0 \forall j$; and

$$
\gamma^{A} \equiv \frac{\mu}{1-\theta}
$$

is the growth rate of TFP of region $i$, which increases with the intensity of spatial externalities $\theta$. Spatial externalities, therefore, have a positive growth effect on regional TFP, which is the main departure from a standard Solovian exogenous growth model (see Ertur and Koch, 2007, p. 1038).

The importance of spatial externalities in the analyses of regional growth has been emphasized by a large literature (see, e.g., Abreu et al., 2004 and Tselios, 2009 for details and references). Moreover, the view of spatial externalities as technological externalities is very common (in addition to Bottazzi and Peri, 2003 and Ertur and Koch, 2007, see LópezBazo et al., 2004, Fingleton and López-Bazo, 2006, and Elhorst et al., 2010). Finally, in the literature at country level, Aghion and Jaravel (2015) argue that technological advances of a country are the result of shifts in its own technological frontier and of imitation of foreign technology, i.e. of knowledge spillovers.

Vector $\left(w_{i 1}, \ldots, w_{i N}\right)$ accounts for the observed cross-section dependence of region $i$ 's technology on other regions' technology. Equation (3) should be interpreted as represent-

\footnotetext{
${ }^{7}$ Differently, following the literature on endogenous growth, Ertur and Koch (2007) assume that technological progress is a by-product of the accumulation of physical capital. Moreover, they neglect possible sources of heterogeneity across regions given by different values of $\Omega_{i 0}$.
} 
ing the outcome of complex phenomena including both the interactions between firms of different regions and the mobility of workers across different regions. The crucial factors affecting these phenomena are both geographical proximities and technological proximities (see Boschma, 2005, Basile et al., 2012, Comin et al., 2012 and Aghion and Jaravel, 2015). Hence in the empirical analysis we will model the spatial weights matrix $\mathbf{W}$ as depending on the geographical and technological proximity among regions.

As in the standard Solovian growth model, assume that the investment rate of region $i$ is constant and equal to $s_{i}$ and that $L_{i t}$ grows at constant rate $n_{i}$. Therefore, the equation describing the accumulation of (per worker) capital of region $i, k_{i t} \equiv K_{i t} / L_{i t}$, is given by:

$$
\dot{k}_{i t}=s_{i} y_{i t}-\left(\delta+n_{i}\right) k_{i t},
$$

where $y_{i t} \equiv Y_{i t} / L_{i t}$ is GDP per worker and $\delta$ is the depreciation rate of capital (assumed for the sake of simplicity equal for all regions). From Equations (1), (3), and (5) we can calculate the equilibrium level of capital in efficiency units, and therefore the equilibrium level of GDP per efficiency units $\tilde{y}_{i}^{\infty} \equiv y_{i}^{\infty} / A_{i}^{\infty}$ :

$$
\tilde{y}_{i}^{\infty}=\left[\frac{G\left(f_{i}\right) s_{i}}{\delta+n_{i}+\gamma^{A}}\right]^{\frac{\alpha}{1-\alpha}} .
$$

In the long-run equilibrium (i.e. in the balanced growth path) the growth rate of $y_{i}, \gamma_{i}^{\infty}$, is therefore equal to the growth rate of $A_{i}$ :

$$
\gamma_{i}^{\infty}=\gamma^{A}=\frac{\mu}{1-\theta}
$$

i.e. the intensity of spatial externalities affects the long-run growth rate. Therefore, in equilibrium the level of funds $f_{i}$ affects only the level of GDP per worker but not the growth rate. 


\section{Empirical Analysis}

In this section we use the spatial growth model of Section 4 to estimate the impact of EU funds on growth of regional per worker GDP. The section is organized as follows: Section 5.1 derives from the theoretical model the econometric specification to be estimated; Section 5.2 gathers the main results of the estimation; Section 5.3 assesses the effectiveness of Cohesion Policy on growth and regional disparities.

\subsection{From the Theoretical Model to the Econometric Specifica- tion}

Following Durlauf et al. (2005, p. 577), the log-linearization of the dynamics around the long-run equilibrium allows to express the average growth rate of GDP per worker of region $i$ in the period $[t-\tau, t], \gamma_{i t}$ (i.e. $\tau$ are the number of years within the period) as:

$$
\gamma_{i t} \approx \gamma^{A}+\beta\left(\ln \tilde{y}_{i, t-\tau}-\ln \tilde{y}_{i t}^{\infty}\right)
$$

where $\beta \equiv-\left(1-e^{-\lambda \tau}\right) / \tau<0$, and $\lambda>0$ measures the rate of convergence of of region $i$ 's GDP per worker to its equilibrium $\tilde{y}_{i t}^{\infty}$. The slight difference with respect to Durlauf et al. (2005) is due to the need to take into account the panel dimension of our analysis. We have added a time index $t$ to the long-run equilibrium of GDP per worker because in the panel estimate it may change across different periods (see Shioji, 2001).

Substituting Equations (6) and (3) in Equation (8) (recalling that $\tilde{y}_{i, t-\tau} \equiv y_{i, t-\tau} / A_{i, t-\tau}$ ), we obtain:

$$
\begin{aligned}
\gamma_{i t} & \approx \gamma^{A}+\beta\left[\ln y_{i, t-\tau}-\nu_{i i} \ln \psi\left(f_{i t}\right) \Omega_{i, t-\tau}-\sum_{j=1, j \neq i}^{N} \nu_{i j} \ln \psi\left(f_{j t}\right) \Omega_{j, t-\tau}+\right. \\
& \left.-\left(\frac{\alpha}{1-\alpha}\right) \ln \left(\frac{G\left(f_{i t}\right) s_{i t}}{\delta+n_{i t}+\gamma^{A}}\right)\right],
\end{aligned}
$$

where $f_{i t}, s_{i t}$ and $n_{i t}$ are respectively the average EU funds, saving rate and growth rate of employment in the period $[t-\tau, t]$. We assumed that $f_{i, t-\tau} \approx f_{i t}$, that is yearly amounts 
of funds are equal in the period $[t-\tau, t]$.

Equation (9) shows that the observed growth rate of GDP per worker of region $i$ depends on: i) the exogenous growth rate of technological progress $\gamma^{A}$; ii) the level of EU funding $f_{i t}$; iii) the region-specific Solovian growth determinants $s_{i t}$ and $n_{i t}$; iii) the initial level of technological progress $\Omega_{i, t-\tau}$ and GDP per worker $y_{i, t-\tau}$; and iv) the spatially weighted EU funding and spatially weighted neighbouring regions' initial levels of technology $\sum_{j=1, j \neq i}^{N} \nu_{i j} \ln \psi\left(f_{j t}\right) \Omega_{j, t-\tau}$.

From Equation (9) it is possible to identify the direct and indirect effects of EU funds on the growth rate of GDP per worker of region $i$ (we adopt a terminology used in the spatial econometrics literature, see LeSage and Pace, 2009, and Section 5.3) corresponding to the unmediated and mediated effects of funds. In particular, a change in the allocation of EU funds among the regions affects $\gamma_{i t}$ as follows:

$$
d \gamma_{i t}=\sum_{j=1}^{N} \frac{\partial \gamma_{i t}}{\partial f_{j t}} d f_{j t}
$$

i.e.:

$$
d \gamma_{i t}=-\beta\left[\sum_{j=1}^{N} \nu_{i j} \epsilon_{\psi} d f_{j t}+\frac{\alpha}{1-\alpha} \epsilon_{G} d f_{i t}\right]
$$

where:

$$
\epsilon_{\psi} \equiv \frac{\psi\left(f_{j t}\right)^{\prime}}{\psi\left(f_{j t}\right)} \text { and } \epsilon_{G} \equiv \frac{G\left(f_{j t}\right)^{\prime}}{G\left(f_{j t}\right)}
$$

are measures of (absolute) elasticity of $\psi(\cdot)$ and $G(\cdot)$ with respect to $f_{j t}$. Assuming that such elasticities are constant, $d \gamma_{i t}$ can be expressed as:

$$
d \gamma_{i t}=-\beta\left[\left(\epsilon_{\psi} v_{i i}+\frac{\alpha}{1-\alpha} \epsilon_{G}\right) d f_{i t}+\epsilon_{\psi} \sum_{j \neq i, j=1}^{N} \nu_{i j} d f_{j t}\right] .
$$

Finally, assuming that $d f_{i t}=d f_{j t}=d f_{t} \forall j$, we have that the total effect of funds on $\gamma_{i t}$ is 
given by:

$$
\begin{aligned}
\frac{d \gamma_{i t}}{d f_{t}} & =-\beta\left(\epsilon_{\psi} v_{i i}+\frac{\alpha}{1-\alpha} \epsilon_{G}\right)-\beta \epsilon_{\psi} \sum_{j \neq i, j=1}^{N} \nu_{i j}= \\
& =\underbrace{-\beta\left[\epsilon_{\psi}\left(1+\sum_{r=1}^{\infty} \theta^{r} w_{i i}{ }^{(r)}\right)+\frac{\alpha}{1-\alpha} \epsilon_{G}\right]}_{\text {direct effect }} \underbrace{-\beta \epsilon_{\psi} \sum_{j \neq i, j=1}^{N} \sum_{r=1}^{\infty} \theta^{r} w_{i j}{ }^{(r)}}_{\text {indirect effect }} .
\end{aligned}
$$

The first term in Equation (13) represents the direct effect on $\gamma_{i t}$ of an increase in the funds of region $i$ once the spatial externalities generated by such increase are considered, while the second term represents the indirect effect on $\gamma_{i t}$ of an increase in the funds of all the other regions. Both the direct and indirect effects positively depend on $\theta$ and $w_{i j}$ (remember that $\beta<0$ ).

Two last steps are needed to complete the specification of the econometric model. The first consists in adopting a flexible specification of both $\psi(\cdot)$ and $G(\cdot)$ as the following:

$$
\begin{aligned}
\psi\left(f_{i, t}\right) & =e^{\eta_{1}^{\psi} f_{i, t}+\eta_{2}^{\psi} f_{i, t}^{2}} \\
G\left(f_{i, t}\right) & =e^{\eta_{1}^{G} f_{i, t}+\eta_{2}^{G} f_{i, t}^{2}},
\end{aligned}
$$

which satisfies the restrictions on the shape of $G(\cdot)$ and $\psi(\cdot)$, i.e. $G(0)=\psi(0)=1$ and $G(\cdot)>0$ and $\psi(\cdot)>0$. In addition, it allows for the presence of nonlinearities, that recent works have found in the effect of Objective 1 funds (see Becker et al., 2012 and Pellegrini et al., 2013).

The second is represented by the definition of the initial level of technological progress $\Omega_{i, t-\tau}$ which, following Mankiw et al. (1992), should reflect not only technological factors, but also economy-specific characteristics affecting growth, such as resource endowments, climate and quality of institutions. Therefore, we assume that:

$$
\ln \Omega_{i, t-\tau}=\ln \bar{\Omega}+d_{t-\tau}+\pi Z_{i, t-\tau}
$$

that is, the heterogeneity in the initial technological levels of regions is the result of the sum of a constant factor equal across all regions $(\bar{\Omega})$, a time-dependent factor equal across all 
regions $\left(d_{t-\tau}\right)$, capturing possible common trends, and a set of additional control variables $Z_{i, t-\tau}$ (which can also include time-invariant unobservable regional characteristics) specific to the region.

Substituting Equations (14)-(15) in Equation (9), rearranging terms in order to get an estimable spatial model, and adding an error term $e_{i t}$ to take into account the possibility of region-specific shocks, with $E\left[e_{i t}\right]=0$ and $E\left[e_{i t}^{2}\right]=\sigma_{e}^{2} \forall i, t$, leads to (see Appendix B):

$$
\begin{aligned}
\gamma_{i t} & =\mu-\beta \ln \bar{\Omega}-\beta d_{t-\tau}+\beta \ln y_{i, t-\tau}-\beta\left[\eta_{1} f_{i, t}+\eta_{2} f_{i, t}^{2}\right]+ \\
& -\beta\left(\frac{\alpha}{1-\alpha}\right) \ln s_{i t}+\beta\left(\frac{\alpha}{1-\alpha}\right) \ln \left(\delta+n_{i t}+\gamma^{A}\right)-\beta \pi Z_{i, t-\tau}+ \\
& -\theta \beta\left[\sum_{j=1}^{N} w_{i j} \ln y_{j, t-\tau}\right]+\theta \beta\left(\frac{\alpha}{1-\alpha}\right)\left[\sum_{j=1}^{N} w_{i j}\left(\eta_{1}^{G} f_{j, t}+\eta_{2}^{G} f_{j, t}^{2}\right)\right]+ \\
& +\theta \beta\left(\frac{\alpha}{1-\alpha}\right)\left[\sum_{j=1}^{N} w_{i j} \ln s_{j, t}\right]-\theta \beta\left(\frac{\alpha}{1-\alpha}\right)\left[\sum_{j=1}^{N} w_{i j} \ln \left(\delta+n_{j, t}+\gamma^{A}\right)\right]+ \\
& +\theta \sum_{j=1}^{N} w_{i j} \gamma_{j t}+e_{i t},
\end{aligned}
$$

where $\eta_{1} \equiv \eta_{1}^{\psi}+\eta_{1}^{G} \alpha /(1-\alpha)$ and $\eta_{2} \equiv \eta_{2}^{\psi}+\eta_{2}^{G} \alpha /(1-\alpha)$.

Equation (16) can be expressed in matrix form as:

$$
\gamma_{t}=\phi_{0}+\phi_{t}+\mathbf{X}_{t} \phi_{X}+\mathbf{Z}_{t-\tau} \phi_{Z}+\mathbf{W} \mathbf{X}_{t} \phi_{W X}+\theta \mathbf{W} \gamma_{t}+\mathbf{e}_{t}
$$

where $\gamma_{t}$ is the $(N \times 1)$ vector of average growth rates of GDP per worker in period $[t-\tau, t]$; $\phi_{0}$ includes all constant terms; $\phi_{t}$ is a time-dummy variable; $\mathbf{X}_{t}$ is the $\left(N \times K_{X}\right)$ matrix of Solovian growth determinants (investment rates, the augmented employment growth rates and the initial level of GDP per worker) and EU funds of period $[t-\tau, t] ; \mathbf{Z}_{t-\tau}$ is the $\left(N \times K_{Z}\right)$ matrix of additional control variables, which include also time-constant unobservable characteristics; $\mathbf{W}$ is the row-standardized $(N \times N)$ spatial weight matrix specifying the spatial dependence structure among observations; $\mathbf{W X}_{t}$ is the $\left(N \times K_{X}\right)$ matrix of spatially lagged $\mathbf{X}$ variables; and $\mathbf{W} \gamma_{t}$ is the endogenous spatial lag variable. Coefficients $\phi_{0}, \phi_{t}, \phi_{X}, \phi_{Z}$, and $\phi_{W X}$ are (vectors of) coefficients to be estimated.

Equation (17) represents the basis of the econometric model used in the estimation in 
Section 5.2 below. Its specification, not significantly different from Ertur and Koch (2007), belongs to the class of Spatial Durbin Models (SDMs) (see Anselin, 1988). According to our theoretical growth model, an econometric model including only the spatially-lagged value of the growth rate, as in, e.g., Mohl and Hagen (2010), is therefore plagued by an omitted variable problem.

\subsection{The Estimation of the Model for European Regions}

The sample used in the estimations is composed by 175 NUTS2 regions of EU-12 countries for the period 1991-2008. Our dependent variable is the annual average growth rate of GDP per worker of a region (see Appendix D for the descriptive statistics). In our baseline estimation we include as explanatory variables the standard Solovian growth determinants, i.e. the (log of) initial GDP per worker normalized with respect to sample average to take into account possible global trends (log.PROD.REL.INI), the (log of) average annual investment rate (log.INV.RATE), the (log of) average annual employment growth rate (log.EMP.GR) ${ }^{8}$ the share of funds on regional GDP with a two-year lag (either total funds (SCF), or a breakdown of funds among Cohesion Funds (CF), Objective 1 funds (OB1), Objective 2 funds (OB2), and all the "Other Objectives" funds (OtherOB)). We use a two-year lag when considering the effect of funds on growth to take into account that the effect of the funds on GDP per worker can be delayed. This also aims at reducing the possible endogeneity of the funds with respect to the growth rate of GDP per worker. Finally, a two-year lag allows to exclude from the analysis the recent severe financial crisis. ${ }^{9}$ In the robustness checks, following Mankiw et al. (1992), we will introduce the level of human capital (albeit at national level) as additional determinant of the equilibrium of GDP per worker. ${ }^{10}$

\footnotetext{
${ }^{8}$ The average growth rate of employment is augmented by the rate of depreciation of capital, but not by the long-run trend of GDP per worker, as the latter is already taken into account by considering relative GDP per worker. Given that we have no data on depreciation at regional level, we use the value of 0.03 proposed by Mankiw et al. (1992).

${ }^{9}$ Results are robust to alternative specifications of lags (in particular, a three-year lag).

${ }^{10}$ Mankiw et al. (1992) consider human capital as an additional factor of production, but the unavailability of data on human capital at regional level for the whole period 1991-2008 has suggested us not to consider this possibility in the theoretical framework from the beginning. As a source of human capital data at country level we use the index $h c$ provided in the Penn World Table, version 8.0 (see Feenstra et al., 2015).
} 
Following Boschma (2005), we test alternative specifications of the spatial weights matrix. In particular we consider two measures for both geographical proximity and technological proximity. For geographical proximity we consider two alternative matrices with row-standardized elements $(i, j)$, which are proportional to the inverse of the great circle distance between the centroids of regions $i$ and $j$ (matrix $\mathbf{W}^{D}$ ), or based on travel times by roads in 1991 (matrix $\mathbf{W}^{T T}$ ). ${ }^{11}$ For technological proximity we consider a matrix based on the (di)similarity of output composition of regions, denoted by $\mathbf{W}^{O}$, and a matrix based on the sectoral distribution of patents, denoted by $\mathbf{W}^{P}$ (see Basile et al., 2012, and Marrocu et al., 2013). ${ }^{12}$ Both matrices proxy for the absorptive capacity of knowledge by a region, but while $\mathbf{W}^{O}$ mainly aims at capturing the capacity of absorbing existing technologies, $\mathbf{W}^{P}$ refers to the capacity of absorbing new technologies (Marrocu et al., 2013). In addition, we consider the four possible combinations of the two types of proximities, where distance is given by a geometric weighted mean of the geographical and technological proximity, with $\varphi$ measuring the weight of geographical proximity (see Appendix E for more details). The use of matrices computed at the initial period should make them exogenous with respect to our analysis.

In the estimations the two programming periods I and II are considered as an unique period because they share a relative homogeneity in the rules governing the allocation of funds, while these rules significantly changed in the programming period 2000-2006. Therefore, in the panel analysis we will consider two periods: 1991-2001 and 2002-2008. The investment rate and employment growth are averaged across the two periods, while the initial GDP per worker is taken at the beginning of each period. The estimated models are based on Equation (17), which represents an unrestricted version of the model in Equation (16). ${ }^{13}$

\footnotetext{
${ }^{11}$ Matrix $\mathbf{W}^{T T}$ has been provided by TCP International (https://www.tcp-international.de/en/).

${ }^{12}$ Data for the calculation of matrix $\mathbf{W}^{O}$ are from Cambridge Econometrics (2010), which contains data on output composition of regions up to 10 sectors in 1992, while in the calculation of matrix $\mathbf{W}^{P}$ we use data on the number of patent applications in 8 sectors in 1991-1993 from Eurostat (http: //ec.europa.eu/eurostat/web/products-datasets/-/tsc00009).

${ }^{13}$ Tests for the joint restrictions on coefficients implied by the theoretical model in Equation (16) are generally rejected. Given that these restrictions strictly depend on the assumption of a Cobb-Douglas production function, this is not to be considered a relevant drawback in the analysis. In this respect, the crucial restrictions to be tested in the estimates will be instead the sign of the coefficients.
} 
Equation (16) suggests to insert in the model both time dummies and fixed effects. In particular, the introduction of fixed effects is motivated by the fact that unobserved regional factors that may affect GDP per worker growth such as, for example, institutional quality and cultural values (which are very stable in time), are very likely to be correlated with other growth determinants included in the model (e.g. investment rates).

SCF (or the different types of funds) are potentially endogenous. In principle the allocation of the funds is non-random, but conditional on the regional per capita GDP, implying a potential reverse causality of GDP per worker growth on funds. Moreover, the endogeneity of funds could also arise by the measurement error induced by the use of commitments instead of payments, and by our reassignment of some funds to NUTS2 regions.

We therefore estimate a spatial panel fixed effect model, robust to endogeneity via two-stage maximum likelihood (see Appendix F for details). ${ }^{14}$ Appendix $\mathrm{F}$ gathers the details on the instrumental variables used to control for the endogeneity of funds, the test of endogeneity, and the test of over-identifying restrictions for the validity of the instrumental variables.

\subsubsection{Estimation Results}

Table 4 reports the estimated coefficients of three models: Model I, in which funds are aggregated; Model II, where funds are disaggregated by objectives; and Model III, which includes human capital among the covariates. The estimates refer to the optimal combination of spatial weights matrices $\mathbf{W}^{D O}$, based on $\mathbf{W}^{D}$ and $\mathbf{W}^{O}$ with $\varphi=0.8$. In particular, Appendix $\mathrm{G}$ shows that for models with disaggregated funds $\mathbf{W}=\mathbf{W}^{D O}$ with $\varphi=0.8$ minimizes the value of AICc for the four types of possible combinations of the two types of proximity (i.e. $\mathbf{W}^{D O}, \mathbf{W}^{T T O}, \mathbf{W}^{D P}$, and $\mathbf{W}^{T T P}$ ), for the values of $\varphi$ in the range $[0,1]$ (see Anderson, 2007 for the use of AICc for model selection). The estimation results with individual matrices $\mathbf{W}^{D}, \mathbf{W}^{T T}, \mathbf{W}^{O}$, and $\mathbf{W}^{P}$ are reported in Appendix $\mathrm{G}$. They show that the sign of coefficients reported in Table 4 are largely robust to alternative

\footnotetext{
${ }^{14}$ Murphy and Topel (1985) discuss how the two-stage maximum likelihood procedure provides consistent estimators of the parameters. See also Brunetti et al. (2016) for details.
} 
specifications of the spatial weights matrix W. In terms of goodness of fit, none of these specifications outperform the one with $\mathbf{W}^{D O}$ and $\varphi=0.8$.

The values of the LR test and of the test of over-identifying restrictions (reported in the last two rows of Table 4) suggest that endogeneity is present in all models and instruments are valid. Appendix $\mathrm{H}$ report the first-stage regressions for the control of endogeneity for Model II, which represents our preferred specification on the basis of AICc. The generalized $\bar{R}^{2}$ never below 0.8 points out that models are able to explain a large share of the observed variance of growth among the regions. Spatial effects appear remarkably large: the estimated parameters $\theta$ take on values between 0.65 and 0.7 and are always significant at 5\% significance level. European regions of our sample display conditional convergence as predicted by the theoretical model: the sign of the coefficient of initial GDP per worker is negative and statistically significant irrespectively of the model specification. Employment growth has the predicted negative sign, while investment rate has negative signs but its coefficient is only marginal significant as found in other works (see, e.g., Fiaschi and Lavezzi, 2007 and Mohl and Hagen, 2010). Model III shows that including human capital slightly worsen the goodness of fit in terms of the AICc, and leaves basically unaffected the estimated coefficients of other variables. The sign of the coefficient of human capital is positive and significant only at $10 \%$.

$\mathrm{SCF}$ has a positive and concave significant effect on regional growth. There is also evidence of a significant effect of the same sign of the spatially-lagged SCF. The disaggregation of funds uncovers crucial differences among funds: all types of funds have a non-significant coefficient, while the coefficients of their spatially-lagged values are significant for Objective 1 and "Other Objectives" funds, while non-significant for Objective 2 and Cohesion Fund. This evidence suggests that Objective 1 funds have a increasing but concave effect. ${ }^{15}$

\footnotetext{
${ }^{15}$ As shown by Table 12 in Appendix I the estimation of Model II using the annual growth rate of GDP per capita as the dependent variable produces similar results.
} 


\begin{tabular}{|c|c|c|c|}
\hline Dependent variable & \multicolumn{3}{|c|}{ Average annual growth rate of GDP per worker } \\
\hline Spatial Matrix & \multicolumn{3}{|c|}{$\mathbf{W}^{D O}(\varphi=0.8)$} \\
\hline Model & I & II & III \\
\hline Funds & SCF & All Obj. & All Obj. \\
\hline REGIONAL FE & YES & YES & YES \\
\hline TIME DUMMIES & YES & YES & YES \\
\hline log.PROD.REL.IN & $\begin{array}{l}-0.070 \\
(0.000)\end{array}$ & $\begin{array}{l}-0.070 \\
(0.000)\end{array}$ & $\begin{array}{l}-0.067 \\
(0000)\end{array}$ \\
\hline log.INV.RATE & $\begin{array}{c}-0.007 \\
(0.009)\end{array}$ & $\begin{array}{c}-0.005 \\
(0.083)\end{array}$ & $\begin{array}{l}-0.005 \\
(0.111)\end{array}$ \\
\hline log.EMP.GR & $\begin{array}{l}-0.009 \\
(0.000)\end{array}$ & $\begin{array}{l}-0.010 \\
(0.000)\end{array}$ & $\begin{array}{l}-0.010 \\
(0.000)\end{array}$ \\
\hline $\mathrm{HC}$ & & & $\begin{array}{l}0.014 \\
(0.056)\end{array}$ \\
\hline W.log.PROD.REL.IN & $\begin{array}{l}0.054 \\
(0.000)\end{array}$ & $\begin{array}{l}0.056 \\
(0.000)\end{array}$ & $\begin{array}{l}0.045 \\
(0.026)\end{array}$ \\
\hline W.log.INV.RATE & $\begin{array}{l}-0.035 \\
(0.000)\end{array}$ & $\begin{array}{l}-0.033 \\
(0.023)\end{array}$ & $\begin{array}{c}-0.036 \\
(0.012)\end{array}$ \\
\hline W.log.EMP.GR & $\begin{array}{l}0.007 \\
(0.363)\end{array}$ & $\begin{array}{l}0.003 \\
(0.721)\end{array}$ & $\begin{array}{l}0.004 \\
(0.620)\end{array}$ \\
\hline W.HC & & & $\begin{array}{l}-0.026 \\
(0.075) \\
\end{array}$ \\
\hline$\overline{\mathrm{SCF}}$ & $\begin{array}{l}0.300 \\
(0.002)\end{array}$ & & \\
\hline $\mathrm{SCF}^{2}$ & $\begin{array}{l}-2.780 \\
(0.002)\end{array}$ & & \\
\hline W.SCF & $\begin{array}{l}2.996 \\
(0.000)\end{array}$ & & \\
\hline W.SCF ${ }^{2}$ & $\begin{array}{c}-34.857 \\
(0.000)\end{array}$ & & \\
\hline OB1 & & $\begin{array}{l}0.148 \\
(0.229)\end{array}$ & $\begin{array}{l}0.146 \\
(0.237)\end{array}$ \\
\hline $\mathrm{OB} 1^{2}$ & & $\begin{array}{l}-0.957 \\
(0.456)\end{array}$ & $\begin{array}{c}-0.802 \\
(0.532)\end{array}$ \\
\hline OB2 & & $\begin{array}{l}0.028 \\
(0.983)\end{array}$ & $\begin{array}{l}-0.135 \\
(0.919)\end{array}$ \\
\hline OtherOB & & $\begin{array}{c}-0.041 \\
(0.788)\end{array}$ & $\begin{array}{l}-0.023 \\
(0.883)\end{array}$ \\
\hline $\mathrm{CF}$ & & $\begin{array}{l}-0.701 \\
(0.237)\end{array}$ & $\begin{array}{c}-0.792 \\
(0.179)\end{array}$ \\
\hline W.OB1 & & $\begin{array}{l}2.002 \\
(0.000)\end{array}$ & $\begin{array}{l}1.965 \\
(0.001)\end{array}$ \\
\hline W.OB1 ${ }^{2}$ & & $\begin{array}{c}-33.909 \\
(0.000)\end{array}$ & $\begin{array}{c}-33.553 \\
(0.000)\end{array}$ \\
\hline W.OB2 & & $\begin{array}{l}5.352 \\
(0.346)\end{array}$ & $\begin{array}{l}6.704 \\
(0.248)\end{array}$ \\
\hline W.OtherOB & & $\begin{array}{l}2.811 \\
(0.012)\end{array}$ & $\begin{array}{l}2.772 \\
(0.020)\end{array}$ \\
\hline W.CF & & $\begin{array}{l}1.516 \\
(0.644)\end{array}$ & $\begin{array}{l}1.607 \\
(0.628)\end{array}$ \\
\hline$\theta$ & $\begin{array}{l}0.660 \\
(0.000)\end{array}$ & $\begin{array}{l}0.680 \\
(0.000)\end{array}$ & $\begin{array}{l}0.683 \\
(0.000)\end{array}$ \\
\hline $\mathrm{N}$ & 350 & 350 & 350 \\
\hline $\mathrm{AICc}$ & -2244.197 & -2176.26 & -2158.93 \\
\hline Generalized $\bar{R}^{2}$ & 0.91 & 0.90 & 0.91 \\
\hline LR test of endogeneity & $\begin{array}{l}45.241 \\
(0.000)\end{array}$ & $\begin{array}{l}17.706 \\
(0.060)\end{array}$ & $\begin{array}{l}18.145 \\
(0.053)\end{array}$ \\
\hline Test of over-identifying restrictions & $\begin{array}{l}0.944 \\
(0.419)\end{array}$ & $\begin{array}{l}1.104 \\
(0.360)\end{array}$ & $\begin{array}{l}1.083 \\
(0.37)\end{array}$ \\
\hline
\end{tabular}

Table 4: Estimation of Model (16) under different specification of spatial weights matrix and disaggregation of funds. P-values in parenthesis. Funds with two-year lags. Spatial weights matrices are defined in Appendix E. Instrumental variables used in the control of endogeneity of funds (lagged funds and instruments derived by the three-group method described in Kennedy, 2008), the test of endogeneity, and the test of over-identifying restrictions for the validity of instrumental variables are discussed in Appendix F. AICc: Akaike criterion for small samples (see Anderson, 2007). Generalized $\overline{\mathbf{R}}^{2}$ : generalization of $\bar{R}^{2}$ for ML estimates (see Nagelkerke, 1991). 


\subsection{The Effectiveness of Cohesion Policy}

In this section we discuss the effectiveness of Cohesion Policy in terms of its impact on growth and regional disparities on the basis of Model II in Table 4.

Table 5 reports the estimates of the average direct, indirect and total effects of funds on GDP per worker growth. The average direct effect is the average impact exerted by the funds on the growth of GDP per worker of recipient regions, which includes the feedback from other regions who enjoyed externalities from that region; the average indirect effect is instead the average impact exerted by the funds allocated to neighbour regions through spatial externalities; the total effect is the sum of two (see LeSage and Pace, 2009). These represent the estimates of their theoretical counterparts discussed in Section 4 (see, in particular, Equation (13)).

\begin{tabular}{l|ccc}
\hline \hline Model & \multicolumn{3}{|c}{ II } \\
\hline Spatial Matrix & \multicolumn{3}{|c}{$\mathbf{W}^{D O}(\varphi=0.8)$} \\
\hline Average Effects & Direct & Indirect & Total \\
\hline \hline OB1 & 0.307 & 6.413 & 6.720 \\
& $(0.031)$ & $(0.024)$ & $(0.021)$ \\
OB1 $^{2}$ & -3.561 & -105.410 & -108.971 \\
& $(0.028)$ & $(0.015)$ & $(0.014)$ \\
OB2 & 0.433 & 16.381 & 16.814 \\
& $(0.785)$ & $(0.258)$ & $0.261)$ \\
OtherOB & 0.168 & 8.488 & 8.656 \\
& $(0.360)$ & $(0.032)$ & $(0.033)$ \\
CF & -0.623 & 3.170 & 2.547 \\
& $(0.349)$ & $(0.789)$ & $(0.836)$ \\
\hline \hline
\end{tabular}

Table 5: Estimation of average direct, indirect and total effects based on the estimation of Models II in Table 4. Dependent variable: annual average growth rate of GDP per worker. P-values in parenthesis are calculated following the Cholesky decomposition proposed by LeSage and Pace (2009).

Both the average direct and indirect effects of Objective 1 funds (and its square) are significant, leading to a significant positive and concave average total effect of OB1 on regional growth; "Other Objectives" funds are the only other type of funds having a significant (indirect and total) positive effect. Overall, (average) indirect effects appear to play a fundamental role in the explanation of the effect of EU funding on regional growth. Le Gallo et al. (2011) also estimate direct and indirect effects of funding but, on average, do not find significant results in the period 1989-1999 for a sample 145 EU regions. When focusing on local effects, i.e. effects characterizing subset of regions, they find that in 
some regions the effects are significantly positive or significantly negative, while in the majority of regions they remain non-significant. Their sample and estimation technique are, however, completely different. On the basis of Equation (13) we can argue that the positive elasticities of output and TFP to funds, $\epsilon_{\psi}$ and $\epsilon_{G}$ respectively, are magnified by the presence of strong spatial externalities, measured by the estimate of $\theta$.

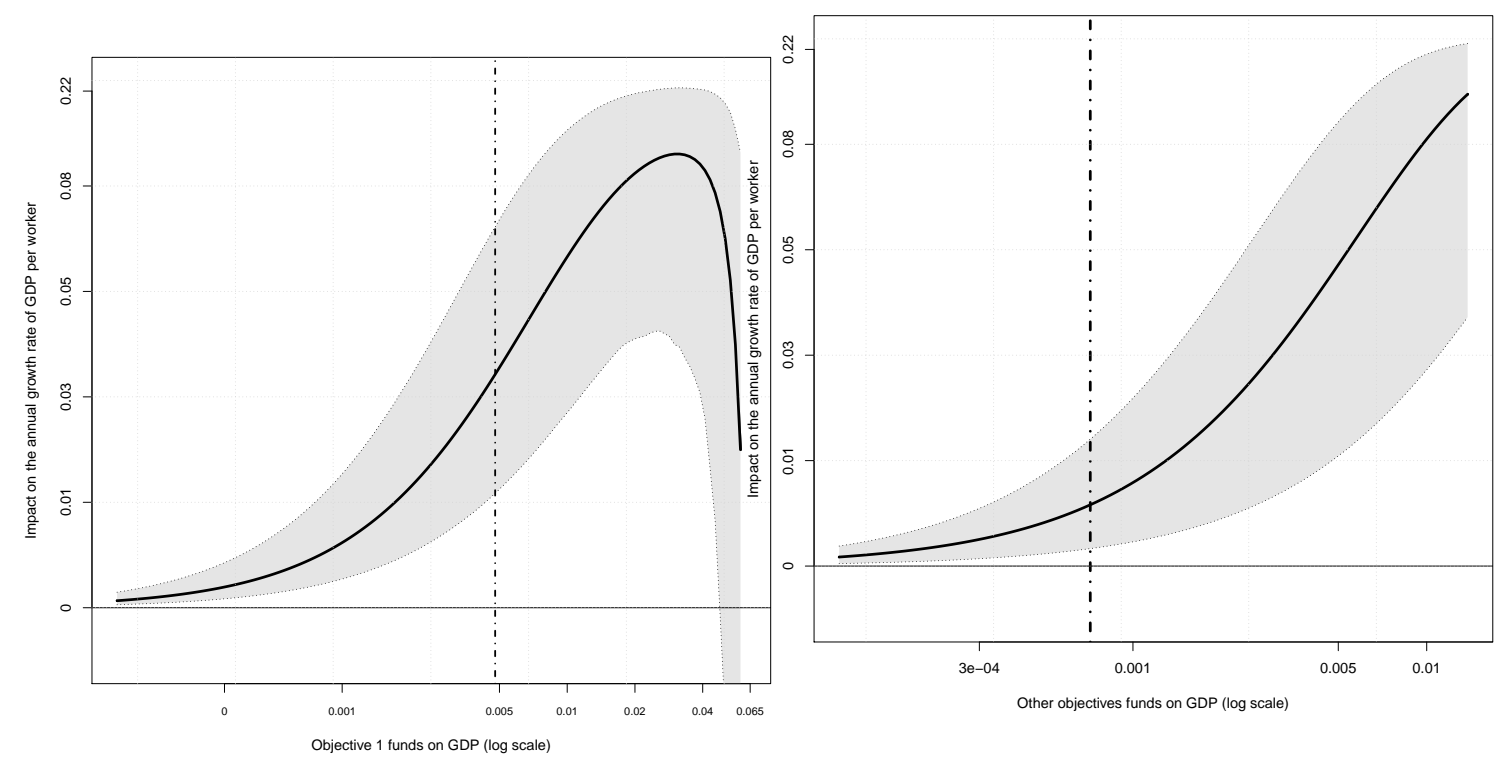

Figure 2: Estimated average total effect on the Figure 1: Estimated average total effect on GDP per worker growth of Other objectives GDP per worker growth of Objective 1 funds funds (gray area represents $95 \%$ confidence in(gray area represents 95\% confidence interval) terval) of Model II in Table 4. Vertical dashfrom Model II in Table 4. Vertical dash-dotted dotted line represents the sample average of the line represents the sample average of the funds. funds.

Figures 1 and 2 provide a graphical illustration of the average total effect of Objective 1 and "Other Objectives" funds respectively with their 95\% confidence bands. Figure 1 shows that Objective 1 funds have an optimal size, which we quantify at approximately $3 \%$ of regional GDP. In addition, there exists a threshold at about $4 \%$ after which Objective 1 funds have no significant effects. Becker et al. (2012) find a similar result, but they estimate such threshold at 1.8\%, for a sample of 1091 EU15 NUTS3 regions in the 1994-1999 programming period and 1213 EU 25 NUTS3 regions in the 2000-2006 programming period. They, however, consider the effect on per capita GDP growth and, more importantly, neglect spatial externalities. For a sample of 122 NUTS-1/NUTS-2 regions over the period 1995-2005 Hagen and Mohl (2008), adopting an empirical strategy similar to Becker et al. (2012), find a concave but non-significant effect of Objective 
1 funds on per capita GDP growth. Also in this case the role of spatial externalities of funds is substantially neglected.

Focusing only on funds with statistically significant effects, Table 6 shows that substantial gains in the effectiveness of Cohesion Policy occurred between the two periods 1991-2001 and 2002-2008. The estimated effect of Objective 1 funds on the median regional growth rate of GDP per worker $\left(\Delta \gamma^{\mathrm{OB} 1}\right)$ is, in fact, $0.24 \%$ in the first period and $0.37 \%$ in the second, ${ }^{16}$ while the corresponding values of the (median) Objective- 1 funds multiplier (mult ${ }^{\mathrm{OB} 1}$ ) are 0.45 and 1.52 respectively (these differences are highly statistically significant). ${ }^{17}$ The changes in the management of Structural and Cohesion Funds between the two periods provide a possible explanation of this rise over time of Objective1 funds multiplier. In particular, Alegre (2012) and Rodríguez-Pose and Novak (2013) contain a thorough discussion of the refinements in the rules governing the allocation and the use of funds between the two periods, emphasizing the attempt to limit the crowdingout of funds on other public investments and, in general, the implementation of better practices in the allocation and management of funds.

\begin{tabular}{|c|c|c|c|}
\hline Model & \multicolumn{3}{|c|}{ II } \\
\hline Spatial Matrix & \multicolumn{3}{|c|}{$\mathbf{W}^{D O}(\varphi=0.8)$} \\
\hline & \multicolumn{3}{|c|}{ Sample median } \\
\hline Period & 1991-2001 & $2002-2008$ & Difference \\
\hline$\Delta \gamma^{\mathrm{OB1}}$ & $\begin{array}{c}0.0024 \\
{[0.0014]}\end{array}$ & $\begin{array}{l}0.0037 \\
{[0.0017]}\end{array}$ & $\begin{array}{c}0.0013 \\
(0.000)\end{array}$ \\
\hline$\Delta \gamma^{\text {OtherOB }}$ & $\begin{array}{c}0.0079 \\
{[0.0039]}\end{array}$ & $\begin{array}{l}0.0005 \\
{[0.0002]}\end{array}$ & $\begin{array}{c}-0.0074 \\
(0.000)\end{array}$ \\
\hline mult ${ }^{\mathrm{OB} 1}$ & $\begin{array}{l}0.45 \\
{[0.54]}\end{array}$ & $\begin{array}{l}1.52 \\
{[0.70]} \\
\end{array}$ & $\begin{array}{c}1.0629 \\
(0.001)\end{array}$ \\
\hline
\end{tabular}

Table 6: The estimated median effect on regional annual growth rate of GDP per worker of Objective 1 $\left(\Delta \gamma^{\mathrm{OB} 1}\right)$ and "Other Objectives" $\left(\Delta \gamma^{\mathrm{OtherOB}}\right)$ funds, the median Objective-1 funds multiplier (mult $\left.{ }^{\mathrm{OB} 1}\right)$ in the two periods 1991-2001 and 2002-2008 (standard errors in square brackets), and the bootstrap test of difference of medians ( $\mathrm{p}$-value in parenthesis).

\footnotetext{
${ }^{16}$ We prefer to take as main index of effectiveness of funds the median instead of average regional growth due to the high skewness of the distribution of Objective 1 funds.

${ }^{17}$ The Objective- 1 funds multiplier of region $i$ over the period $[t-\tau, t]$ is calculated as:

$$
\text { mult }_{i t}^{\mathrm{OB} 1} \equiv \frac{Y_{i t}^{\mathrm{OB} 1}-Y_{i, t-\tau}}{\mathrm{OB}_{i t}} \equiv \frac{\Delta Y_{i t}^{\mathrm{OB} 1}}{\mathrm{OB} 1_{i t}}=\Delta \gamma_{i t}^{\mathrm{OB} 1}\left(\frac{Y_{i, t-\tau}}{\mathrm{OB} 1_{i t}}\right)\left(1+n_{i t}\right)+\left(\frac{Y_{i, t-\tau}}{\mathrm{OB} 1_{i t}}\right) n_{i t}
$$

where $\mathrm{OB}_{i t}$ is the total amount of Objective 1 funds, $\Delta \gamma_{i t}^{\mathrm{OB} 1} \equiv \Delta Y_{i t}^{\mathrm{OB} 1} / L_{i t} /\left(Y_{i, t-\tau} / L_{i, t-\tau}\right)$ the additional growth of GDP per worker in region $i$ due to Objective 1 funds, and $n_{i t} \equiv \Delta L_{i t} / L_{i, t-\tau}$ is the growth rate of employment of region $i$ in period $[t-\tau, t]$.
} 
The effectiveness of "Other Objectives" funds considerably decreased from $0.79 \%$ to $0.06 \%$ between the two periods (this difference is highly statistically significant) as the result of the strong reduction in the amount of this type of funds in 2000-2006 (see Table 2)..$^{18}$

As regards the reduction of regional disparities, Figures 3 and 5 show the geographical concentration of funds: both Objective 1 and the total amount of funds are mainly allocated to the regions of the Southern Europe (Spain, Portugal, Southern Italy, and Greece) plus Ireland. The differences in the intensity of funds are marked: the top quintile in the distribution of total funds (as a ratio to the level of GDP) ranges from $0.77 \%$ to $7.92 \%$ with a sample median of $0.12 \% .{ }^{19}$ Figures 4 and 6 , instead, present the distribution of additional annual growth across the regions of our sample.

The comparison between Figures 3-4 and Figures 5-6 highlights the striking effects of spatial externalities, as several regions not receiving funding had a non-negligible additional growth. Overall, the effect of the Cohesion Policy on regional GDP per worker appears less geographically concentrated and less unequal with respect to funds' allocation, although a strong asymmetry of the benefits remains: the sample median of the estimated additional growth of GDP per worker is equal to 1.4\%, while additional growth in the top quintile ranges from $3.5 \%$ to $5.6 \%$. All the regions in the top quintile belongs to Portugal, Spain, Southern Italy and Greece, while the regions in the bottom quintile are in the core of Europe. The picture is fairly different from the one proposed by Le Gallo et al. (2011) on the spatial distribution of the benefits of EU Cohesion Policy, as they find significant positive effects only in the regions of UK, Southern Italy and Greece.

Finally, the comparison between the distribution of GDP per worker in 2008 and the counterfactual distribution obtained assuming that no EU funding took place ${ }^{20}$ reported in Figure 7, highlights the effectiveness of the Cohesion Policy in acting against the process

\footnotetext{
${ }^{18}$ In Table 6 we do not report the estimate of "Other-Objectives" funds multiplier because the limited amount of this type of funds (just the $3 \%$ of total amount of funds in 2000-2006) makes such estimate not reliable.

${ }^{19}$ In particular, for each of the three programming periods we computed the ratios between the total amount of funds of the period and the initial level of GDP of each programming period; then, we summed the three ratios and took their annual average.

${ }^{20}$ In particular, the counterfactual distribution is calculated by applying to the GDP per worker in 1991 of each region its estimated growth rate from Model II in Table 4, setting to zero the level of funds.
} 


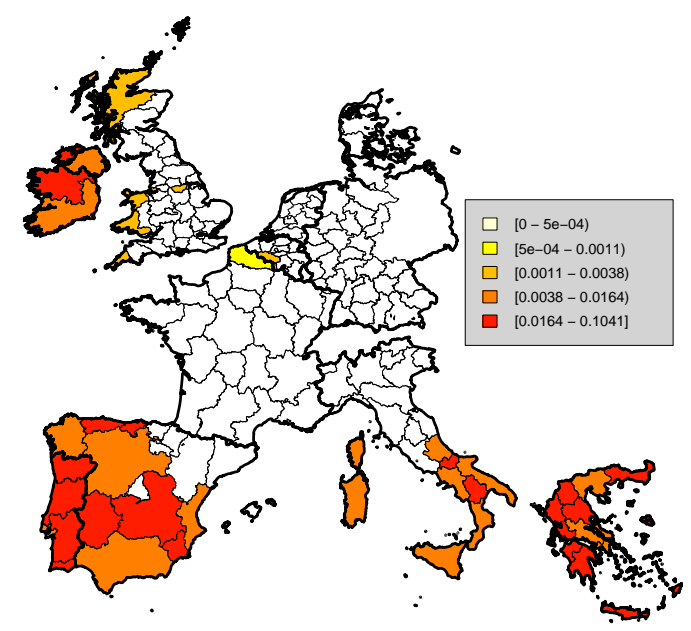

Figure 3: Map of the intensity of Objective 1 funding expressed by the average annual ratio of Objective 1 funds to GDP in the period 19912008 .

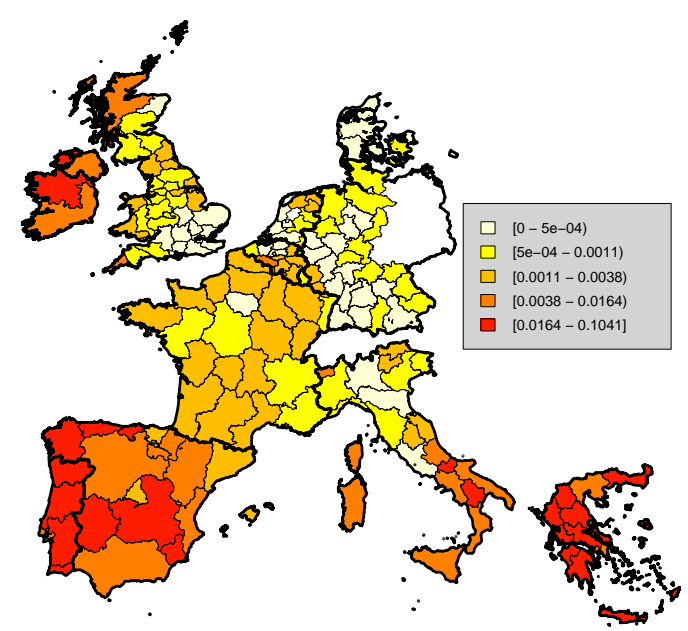

Figure 5: Map of the intensity of total funding expressed by the average annual ratio of total funds to GDP in the period 1991-2008.

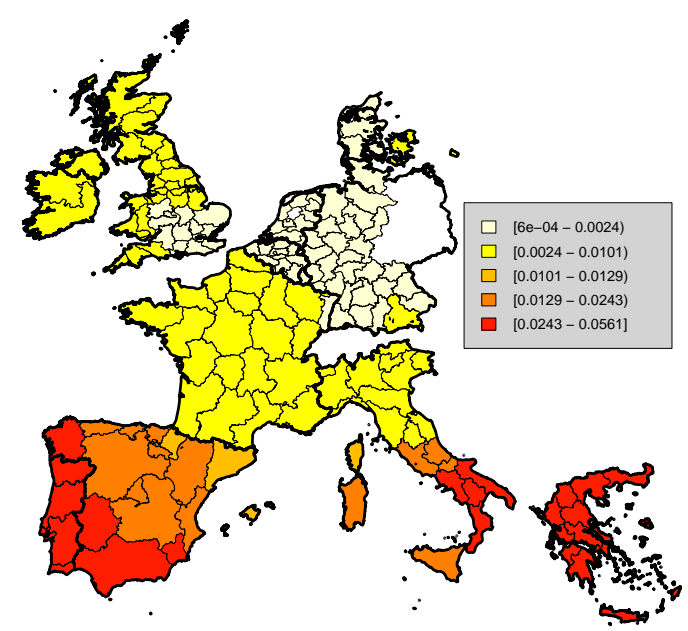

Figure 4: Map of the estimated additional annual growth of GDP per worker ascribable to Objective 1 funds in the period 1991-2008 calculated from Model II in Table 4.

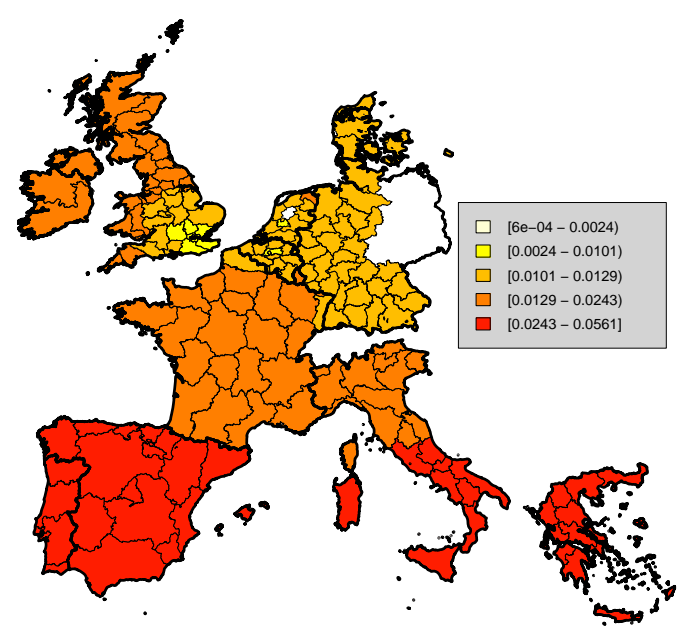

Figure 6: Map of the estimated additional annual growth of GDP per worker ascribable to total funds in the period 1991-2008 calculated from Model II in Table 4. 


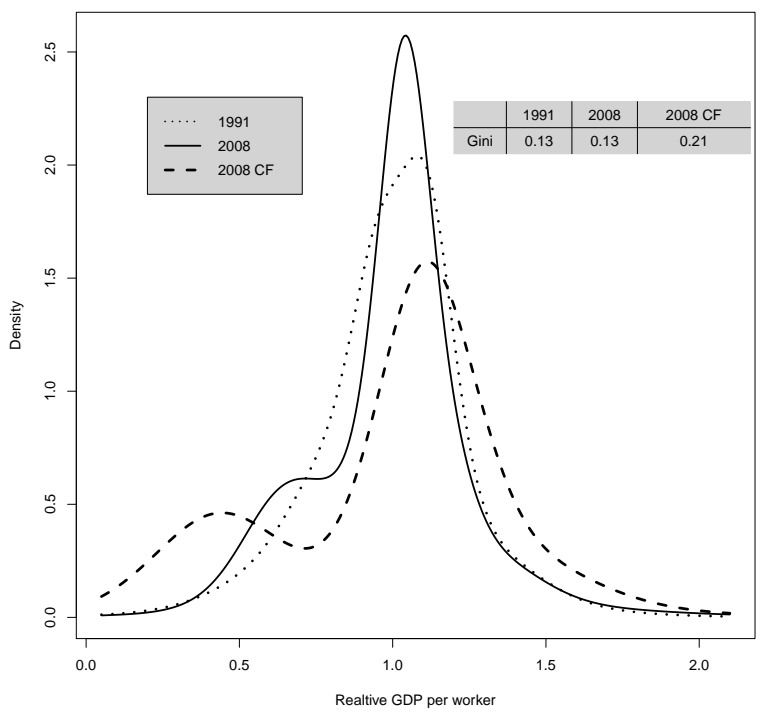

Figure 7: The actual versus the counterfactual distribution of GDP per worker in 2008. The counterfactual distribution is calculated by Model II in Table 4 assuming no contribution of funds to regional growth.

of polarization. According to our estimates, if no funds were allocated over the period 1989-2006 the dispersion of the GDP per worker distribution in 2008 would have been higher by 8 basis points (i.e. the Gini index would have taken on a value of from 0.21 instead of 0.13$)$.

\section{Concluding Remarks}

Our analysis of EU Cohesion Policy allows to address several policy issues raised over time. We provided evidence of a significant effectiveness of the EU Cohesion Policy in the period 1989-2006 in terms of two of its major goals: the increase in regional competitiveness, as measured by the additional annual growth of GDP per worker, which we have quantified for our sample in a median increase of $1.4 \%$, and the reduction of the regional disparities, as measured by the induced decline in Gini index, which we have estimated equal to 8 basis points. This effectiveness is affected by strong spatial spillovers. We found evidence of a significant difference in the effect of the policy over programming periods. In particular, we estimated a median multiplier of Objective 1 funds equal to 1.52 in the period 20022008, a much higher value than 0.45, estimated for the period 1991-2001. This result, at least for Objective 1 funds, is consistent with the claim of Rodríguez-Pose and Novak 
(2013) about a "learning process" in the design of the policy.

Our investigation allows to draw further relevant conclusions for the design of future Cohesion Policy, which appear in line with the suggestions of Barca (2009) and Pieńkowski and Berkowitz (2015). First, Cohesion Policy should be focused on a restricted number of "core priorities" (Barca, 2009), given the evidence that only Objective 1 and the other funds different from Objective 2 and Cohesion funds seems to have had significant effects. Second, the geographical concentration of funds should be favoured, given the presence of significant positive spatial externalities of funds. Third, funds should be more equally allocated across the targeted regions, given the estimated concave effect of Objective 1 funds.

Finally, our findings point to a trade-off between the two goals of EU Cohesion Policy of increasing overall growth and reducing inequalities, which have been already remarked by several authors for the past programming periods (see, e.g., Farole et al., 2011, and Rodríguez-Pose and Novak, 2013). In particular, Southern European regions are both the most peripheral and the poorest. If their economic backwardness and distance from the core of Europe would suggest to allocate to them most of funds to reduce inequalities, the decreasing marginal effect of Objective 1 funds on GDP per worker and their lower (positive) spatial externalities would suggest the opposite to increase overall growth. Barca (2009) contains several insights on how Cohesion Policy should be designed to manage this trade-off from the social and political perspectives. The allocation of European Structural and Investment Funds for the period 2014-2020 has partially incorporated such recommendations, in particular adopting the "smart specialization" concept, which aims at: "promoting innovation in a wide variety of regional settings, and in particular in the heterogeneous environment of European Union (EU) regions" (McCann and Ortega-Argilés, 2015). ${ }^{21}$ Our estimates could provide a complementary contribution in terms of quantitative estimates of such trade-off for possible alternative patterns of funds' allocation.

Our analysis presents some limitations. First, we consider a subset of current recipients of EU funds (even though our sample covers about $70 \%$ of total funds). Moreover, the

\footnotetext{
${ }^{21}$ See also Foray (2014) for a detailed review of the concept of smart specialization and its application to EU Cohesion Policy.
} 
(relatively) low number of observations limited the possibility to test whether the funds of the last programming period had a different (marginal) impact, and whether such an impact can be conditioned to other regional characteristics. In turn, these limitations suggest some of the most promising lines of future research, which include the extension of the sample to new entrant countries; a more detailed analysis of the differential impact EU policy across programming periods, given the radical changes occurring in the most recent years; and, finally, the investigation of the factors enhancing the effectiveness of funds, as the composition of regional output and the quality of institutions. In this respect Becker et al. (2013) and Rodríguez-Pose and Garcilazo (2015) reports a substantial impact of regional institutional quality on the returns of EU policy.

\section{Acknowledgments}

Angela Parenti is grateful to Fondazione Cassa di Risparmio di Lucca for financial support (grant: "Lo Sviluppo Economico delle Regioni Europee: Metodologie Empiriche, Politiche Regionali Europee e Dinamica Settoriale"). We thank seminar participants at the $14^{\text {th }}$ International Workshop in Spatial Econometrics and Statistics, $5^{\text {th }}$ ICEEE Congress in Genova, RSA International Conference in Leuven, $3^{\text {rd }}$ ICEEE Congress in Ancona, Ispra (Joint Research Center of European Commission), Pisa, Naples (Parthenope) and Rome (Luiss), Michele Battisti, Carlo Bianchi, Julie Le Gallo, Stefano Magrini, and, in particular, Paul Elhorst for helpful comments, and Carsten Schurmann for kind assistance with the data. Usual disclaimer applies. 


\section{References}

Maria Abreu, Henri LF De Groot, and Raymond JGM Florax. Space and growth: A survey of empirical evidence and methods. Région et Développement, 21:13-44, 2004.

Philippe Aghion and Xavier Jaravel. Knowledge spillovers, innovation and growth. The Economic Journal, 125(583):533-573, 2015.

J. G. Alegre. An evaluation of EU regional policy. Do structural actions crowd out public spending? Public Choice, 151(1-2):1-21, 2012.

D. R. Anderson. Model Based Inference in the Life Sciences: a Primer on Evidence. New York: Springer Science \& Business Media, 2007.

Paola Annoni and K Kozovska. EU regional competitiveness index. Luxembourg, Europe, 2010.

L Anselin. Spatial Econometrics: Methods and Models. Dordrecht: Kluwer Academic Publishers, 1988.

L Anselin. Spatial econometrics. In B Baltagi, editor, A Companion to Theoretical Econometrics, pages 310-330. Oxford: Blackwell, 2001.

L Anselin. Spatial externalities, spatial multipliers, and spatial econometrics. International Regional Science Review, 26(2):153-166, 2003.

F Barca. Agenda for a reformed cohesion policy; a place-based approach to meeting European Union challenges and expectations. European Communities, 2009.

R. J Barro. Government spending in a simple model of endogenous growth. Journal of Political Economy, 98:S103-S125, 1990.

R Basile, R. Capello, and A. Caragliu. Technological interdependence and regional growth in Europe: Proximity and synergy in knowledge spillovers. Papers in Regional Science, 91(4):697-722, 2012. 
P. H. Becker, S. O.and Egger and M von Ehrlich. Going NUTS: The effect of EU structural funds on regional performance. Journal of Public Economics, 94:578-590, 2010.

S. O. Becker, P. H. Egger, and M von Ehrlich. Too much of a good thing? On the growth effects of the EU's regional policy. European Economic Review, 56(4):648-668, 2012.

S. O. Becker, P. H. Egger, and M von Ehrlich. Absorptive capacity and the growth and investment effects of regional transfers: A regression discontinuity design with heterogeneous treatment effects. American Economic Journal: Economic Policy, 5(4): 29-77, 2013.

M. Beugelsdijk and S.C.W. Eijffinger. The effectiveness of structural policy in the European Union: An empirical analysis for the EU-15 in 1995-2001. Journal of Common Market Studies, 43:37-51, 2005.

M. Boldrin and F. Canova. Inequality and convergence in Europe's regions: Reconsidering European regional policies. Economic Policy, 16:205-253, 2001.

R Boschma. Proximity and innovation: A critical assessment. Regional Studies, 39(1): 61-74, 2005.

L. Bottazzi and G. Peri. Innovation and spillovers in regions: Evidence from European patent data. European Economic Review, 47(4):687-710, 2003.

A. Brandsma, D. A. Kancs, P. Monfort, and A. Rillaers. RHOMOLO: A dynamic spatial general equilibrium model for assessing the impact of cohesion policy. Papers in Regional Science, 94(S1):S197-S221, 2015.

S. Breschi and F. Lissoni. Knowledge spillovers and local innovation systems: A critical survey,. Industrial and Corporate Change, 10(4):975-1005, 2001.

I. Brunetti, D. Fiaschi, L. Gianmoena, and A. Parenti. Volatility in European regions. Papers in Regional Science, 2016.

Cambridge Econometrics. Cambridge Econometrics. Cambridge, 2010. 
A. Cappelen, F. Castellacci, J. Fagerberger, and B. Verspagen. The impact of EU regional support on growth and convergence in the European Union. Journal of Common Market Studies, 41:621-644, 2003.

C. Checherita, C. Nickel, and P. Rother. The role of fiscal transfer for regional economic convergence in Europe. European Central Bank, Working Paper Series, 1029:March, 2009.

Diego A Comin, Mikhail Dmitriev, and Esteban Rossi-Hansberg. The spatial diffusion of technology. National Bureau of Economic Research, 2012.

S. Dall'Erba and Julie Le Gallo. Regional convergence and the impact of European structural funds over 1989-1999: A spatial econometric analysise. Papers in Regional Science, 87:219-244, 2008.

S. Dall'Erba, R. Guillain, and Julie Le Gallo. Impact of structural funds on regional growth: How to reconsider a 9 year-old black-box. Région et Développement, 30:77-99, 2009.

L De Dominicis. Inequality and growth in European regions: Towards a place-based approach. Spatial Economic Analysis, 9:120-141, 2014.

A. De la Fuente and X. Vives. Infrastructure and education as instruments of regional policy: Evidence from Spain. Economic Policy, 10:11-51, 1995.

M. Di Cataldo. The impact of EU objective 1 funds on regional development: Evidence from the U.K. and the prospect of Brexit. Journal of Regional Science, 9:120-141, 2017.

M. Draghi. Hearing at the European parliament's economic and monetary affairs committee. 15 february 2016. 2016. URL https://www.ecb. europa.eu/press/key/date/ 2016/html/sp160215_content.en.html.

S. N. Durlauf, P. Johnson, and J. Temple. Growth econometrics. In S. N. Durlauf and P. Aghion, editors, Handbook of Economic Growth. Elsevier, 2005. 
S. Ederveen, H.L.F. de Groot, and R. Nahuis. Fertile soil for structural funds? A panel data analysis of the conditional effectiveness of European cohesion policy. Kyklos, 59: 17-42, 2006.

P. Elhorst, G. Piras, and G. Arbia. Growth and convergence in a multiregional model with space-time dynamics. Geographical Analysis, 42(3):338-355, 2010.

C. Ertur and W. Koch. Growth, technological interdependence and spatial externalities: Theory and evidence. Journal of Applied Econometrics, 22:1033-1062, 2007.

European Commission. The Fifth Annual Report. European Commission: Brussels, 1995.

European Commission. The Impact of Structural Policies on Economic and Social Cohesion in the Union 1989-99 a First Assessment Presented by Country (October 1996): Regional Development Studies. European Commission: Luxembourg, 1997.

European Commission. The Eleventh Annual Report. European Commission: Luxembourg, 2000.

European Commission. Second Report on Economic and Social Cohesion. European Commission: Luxembourg, 2001b.

T. Farole, A. Rodríguez?Pose, and M. Storper. Cohesion policy in the European Union: Growth, geography, institutions. JCMS: Journal of Common Market Studies, 49(5): 1089-1111, 2011.

Robert C. Feenstra, Robert Inklaar, and Marcel P. Timmer. The next generation of the Penn World Table. American Economic Review, 105(10):3150-3182, 2015.

A. R. Ferrara, P. McCann, G. Pellegrini, D. Stelder, and F Terribile. Assessing the impacts of cohesion policy on EU regions: A non-parametric analysis on interventions promoting research and innovation and transport accessibility. Papers in Regional Science, 2016.

D. Fiaschi and A. M. Lavezzi. Productivity polarization and sectoral dynamics in European regions. Journal of Macroeconomics, 29:612-637, 2007. 
B. Fingleton and E. López-Bazo. Empirical growth models with spatial effects. Papers in Regional Science, 85(2):177-198, 2006.

D Foray. Smart specialisation: opportunities and challenges for regional innovation policy, volume 79. Routledge, 2014.

M. Fortuna, F. Silva, and A Medeiros. A CGE approach to measuring the impacts of EU structural funds in a small open economy. Papers in Regional Science, 95(3):507-39, 2016.

Luisa Gagliardi and Marco Percoco. The impact of European cohesion policy in urban and rural regions. Regional Studies, 51(6):857-868, 2017.

Mara Giua. Spatial discontinuity for the impact assessment of the EU regional policy: The case of Italian objective 1 regions. Journal of Regional Science, 57(1):109-131, 2017.

Tobias Hagen and Philipp Mohl. Which is the right dose of EU cohesion policy for economic growth? 2008.

Peter Kennedy. A guide to econometrics, 6th edition. Oxford: Blackwell, 2008.

Julie Le Gallo, Sandy Dall'Erba, and Rachel Guillain. The local versus global dilemma of the effects of structural funds. Growth and Change, 42(4):466-490, 2011.

J. P. LeSage and R. K. Pace. Introduction to Spatial Econometrics. Boca Ranton: Taylor \& Francis CRC Press, 2009.

Enrique López-Bazo, Esther Vayá, and Manuel Artis. Regional externalities and growth: evidence from European regions. Journal of regional science, 44(1):43-73, 2004.

N Gregory Mankiw, David Romer, and David N Weil. A contribution to the empirics of economic growth. The quarterly journal of economics, 107(2):407-437, 1992.

Emanuela Marrocu, Raffaele Paci, and Stefano Usai. Proximity, networking and knowledge production in Europe: What lessons for innovation policy? Technological Forecasting and Social Change, 80(8):1484-1498, 2013. 
Laia Maynou, Marc Saez, Andreas Kyriacou, and Jordi Bacaria. The impact of structural and cohesion funds on Eurozone convergence, 1990-2010. Regional Studies, 50(7):11271139, 2016.

Philip McCann and Raquel Ortega-Argilés. Smart specialization, regional growth and applications to European Union cohesion policy. Regional Studies, 49(8):1291-1302, 2015.

Eduardo Medeiros. European Union cohesion policy and spain: A territorial impact assessment. Regional Studies, 51(8):1259-1269, 2017.

Giovanni Millo and Gianfranco Piras. splm: Spatial panel data models in R. Journal of Statistical Software, 47(1):1-38, 2012.

Philipp Mohl and Tobias Hagen. Do EU structural funds promote regional growth? New evidence from various panel data approaches. Regional Science and Urban Economics, 40(5):353-365, 2010.

Willem Molle. European cohesion policy. London: Routledge, 2007.

Kevin M Murphy and Robert H Topel. Estimation and inference in two-step econometric models. Journal of Business 85 Economic Statistics, 3:370-379, 1985.

Nico JD Nagelkerke. A note on a general definition of the coefficient of determination. Biometrika, 78(3):691-692, 1991.

D. Neumark and H. Simpson. Place-based policies. In Handbook of Regional and Urban Economics, pages 1197-1287. 2015.

G. Ottaviano and J. F Thisse. Agglomeration and economic geography. In Handbook of Regional and Urban Economics, pages 2563-2608. 2004.

R.K. Pace and J.P. LeSage. Spatial autoregressive local estimation. In A. Getis, J. Mur, and H. Zoller, editors, Spatial Autoregressive Local Estimation., pages 31-52. 2004. 
Angela Parenti. The Impact of Structural and Cohesion Funds on the Productivity Dynamics Across European Regions. Retrieved from the University of Pisa, 2009.

Guido Pellegrini, Flavia Terribile, Ornella Tarola, Teo Muccigrosso, and Federica Busillo. Measuring the effects of European regional policy on economic growth: A regression discontinuity approach. Papers in Regional Science, 92(1):217-233, 2013.

J Pieńkowski and P Berkowitz. Econometric assessments of cohesion policy growth effects: How to make them more relevant for policy makers. Regional Working Paper WP 02/2015, Directorate-General for Regional and Urban Policy: European Commission, 2015.

R Core Team. R: A Language and Environment for Statistical Computing, 2015.

Julián Ramajo, Miguel A Márquez, Geoffrey JD Hewings, and Maria M Salinas. Spatial heterogeneity and interregional spillovers in the European Union: Do cohesion policies encourage convergence across regions? European Economic Review, 52(3):551-567, 2008.

Andrés Rodríguez-Pose and Ugo Fratesi. Between development and social policies: The impact of European structural funds in objective 1 regions. Regional Studies, 38(1): 97-113, 2004.

Andrés Rodríguez-Pose and Enrique Garcilazo. Quality of government and the returns of investment: Examining the impact of cohesion expenditure in European regions. Regional Studies, 49(8):1274-1290, 2015.

Andrés Rodríguez-Pose and Katja Novak. Learning processes and economic returns in European cohesion policy. Investigaciones regionales, (25):7-26, 2013.

Etsuro Shioji. Public capital and economic growth: A convergence approach. Journal of economic growth, 6(3):205-227, 2001.

A B. SWECO International. Final report ERDF and CF regional expenditure (contract no 2007.ce.16.0.at.036). 2008. 
Vassilis Tselios. Growth and convergence in income per capita and income inequality in the regions of the EU. Spatial Economic Analysis, 4(3):343-370, 2009.

J. M. Wooldridge. Econometric Analysis of Cross Section and Panel Data. MIT press, 2010. 


\section{Appendix}

\section{A Derivation of the Level of Technology of a Region}

The technological level of region $i$ at time $t, A_{i t}$, is given by:

$$
A_{i t}=\psi\left(f_{i}\right) \Omega_{i t} \prod_{j \neq i}^{N} A_{j t}^{\theta w_{i j}}
$$

Taking Equation (18) in logs we obtain:

$$
\ln A_{i t}=\ln \psi\left(f_{i}\right) \Omega_{i t}+\theta \sum_{j=1}^{N} w_{i j} \ln A_{j t} .
$$

Then, rewriting Equation (19) in matrix form we obtain:

$$
\tilde{\mathbf{A}}_{t}=\tilde{\mathbf{\Omega}}_{t}+\theta \mathbf{W} \tilde{\mathbf{A}}_{t}
$$

where $\tilde{\mathbf{A}}_{t}$ is the $(N \times 1)$ vector of logarithms of technological progress at period $t, \tilde{\Omega}_{t}$ is the $(N \times 1)$ vector of logarithms of $\psi\left(f_{i}\right) \Omega_{i t}$, and $\mathbf{W}$ is the $(N \times N)$ Markov matrix with friction terms $w_{i j}$. Solving for $\tilde{\mathbf{A}}_{t}$ returns:

$$
\tilde{\mathbf{A}}_{t}=(\mathbf{I}-\theta \mathbf{W})^{-1} \tilde{\mathbf{\Omega}}_{t}
$$

where $\mathbf{I}$ is the $(N \times N)$ identity matrix. From Equation (21), under the assumption that 
$|\theta|<1$, the technological progress of region $i$ can be expressed as:

$$
\begin{aligned}
A_{i t} & =\psi\left(f_{i}\right) \Omega_{i t} \prod_{j=1}^{N}\left[\psi\left(f_{j}\right) \Omega_{j t}\right]^{\sum_{r=1}^{\infty} \theta^{r} w_{i j}^{(r)}}= \\
& =\psi\left(f_{i}\right) \Omega_{i t}\left[\psi\left(f_{i}\right) \Omega_{i t}\right]^{\sum_{r=1}^{\infty} \theta^{r} w_{i i}^{(r)}} \prod_{j=1, j \neq i}^{N}\left[\psi\left(f_{j}\right) \Omega_{j t}\right]^{\sum_{r=1}^{\infty} \theta^{r} w_{i j}^{(r)}}= \\
& =\left[\psi\left(f_{i}\right) \Omega_{i t}\right]^{1+\sum_{r=1}^{\infty} \theta^{r} w_{i i}^{(r)}} \prod_{j=1, j \neq i}^{N}\left[\psi\left(f_{j}\right) \Omega_{j t}\right]^{\sum_{r=1}^{\infty} \theta^{r} w_{i j}^{(r)}}= \\
& =\left[\psi\left(f_{i}\right) \Omega_{i t}\right]^{\nu_{i i}} \prod_{j=1, j \neq i}^{N}\left[\psi\left(f_{j}\right) \Omega_{j t}\right]^{\nu_{i j}},
\end{aligned}
$$

where the terms $w_{i j}^{(r)}$ are the elements of row $i$ and column $j$ of matrix $\mathbf{W}$ to the power of $r, \nu_{i i}=1+\sum_{r=1}^{\infty} \theta^{r} w_{i i}{ }^{(r)}$ and $\nu_{i j}=\sum_{r=1}^{\infty} \theta^{r} w_{i j}{ }^{(r)}$. Assuming $\Omega_{i t}=\Omega_{i 0} e^{\mu t}$ we obtain:

$$
A_{i t}=\left[\psi\left(f_{i}\right) \Omega_{i 0} e^{\mu t}\right]^{\nu_{i i}} \prod_{j=1, j \neq i}^{N}\left[\psi\left(f_{j}\right) \Omega_{j 0} e^{\mu t}\right]^{\nu_{i j}}
$$

Taking Equation (22) in logs, we have:

$$
\begin{aligned}
\ln A_{i t} & =\nu_{i i} \ln \left[\psi\left(f_{i}\right) \Omega_{i 0}\right]+\nu_{i i} \mu t+\sum_{j=1, j \neq i}^{N} \nu_{i j} \ln \left[\psi\left(f_{j}\right) \Omega_{j 0}\right]+\sum_{j=1, j \neq i}^{N} \nu_{i j} \mu t= \\
& =\nu_{i i} \ln \left[\psi\left(f_{i}\right) \Omega_{i 0}\right]+\mu t+\mu t \sum_{r=1}^{\infty} \theta^{r} w_{i i}^{(r)}+\sum_{j=1, j \neq i}^{N} \nu_{i j} \ln \left[\psi\left(f_{j}\right) \Omega_{j 0}\right]+\mu t \sum_{j=1, j \neq i}^{N} \sum_{r=1}^{\infty} \theta^{r} w_{i j}{ }^{(r)}= \\
& =\nu_{i i} \ln \left[\psi\left(f_{i}\right) \Omega_{i 0}\right]+\sum_{j=1, j \neq i}^{N} \nu_{i j} \ln \left[\psi\left(f_{j}\right) \Omega_{j 0}\right]+\left[1+\sum_{r=1}^{\infty} \theta^{r} \sum_{j=1}^{N} w_{i j}{ }^{(r)}\right] \mu t= \\
& =\nu_{i i} \ln \left[\psi\left(f_{i}\right) \Omega_{i 0}\right]+\sum_{j=1, j \neq i}^{N} \nu_{i j} \ln \left[\psi\left(f_{j}\right) \Omega_{j 0}\right]+\left(\frac{1}{1-\theta}\right) \mu t,
\end{aligned}
$$

given the Markovian property that $\sum_{j=1}^{N} w_{i j}{ }^{(r)}=1$ for each $r$. Finally, taking the exponential of Equation (23) we obtain Equation (3). 


\section{B Derivation of the Average Growth Rate of GDP per Worker}

Since $\nu_{i i}=1+\sum_{r=1}^{\infty} \theta^{r} w_{i i}{ }^{(r)}$ and $\nu_{i j}=\sum_{r=1}^{\infty} \theta^{r} w_{i j}{ }^{(r)}$, Equation (9) can be rewritten as:

$$
\begin{aligned}
\gamma_{i t} & \approx \gamma^{A}+\beta \ln y_{i, t-\tau}-\beta \ln \psi\left(f_{i, t}\right)-\beta \ln \Omega_{i, t-\tau}+ \\
& -\beta\left(\frac{\alpha}{1-\alpha}\right)\left[\ln G\left(f_{i t}\right)+\ln s_{i t}-\ln \left(\delta+n_{i t}+\gamma^{A}\right)\right]+ \\
& -\beta \sum_{j=1}^{N} \sum_{r=1}^{\infty} \theta^{r} w_{i j}^{(r)} \ln \psi\left(f_{j, t}\right)-\beta \sum_{j=1}^{N} \sum_{r=1}^{\infty} \theta^{r} w_{i j}^{(r)} \ln \Omega_{j, t-\tau} .
\end{aligned}
$$

Rewriting Equation (24) in matrix form and pre-multiply all terms by $(\mathbf{I}-\theta \mathbf{W})$ leads to:

$$
\begin{aligned}
(\mathbf{I}-\theta \mathbf{W}) \boldsymbol{\gamma}_{t} & =\gamma^{A}(\mathbf{I}-\theta \mathbf{W}) \mathbb{1}+\beta(\mathbf{I}-\theta \mathbf{W}) \tilde{\mathbf{y}}_{t-\tau}-\beta\left(\frac{\alpha}{1-\alpha}\right)(\mathbf{I}-\theta \mathbf{W})\left(\tilde{\boldsymbol{G}}_{t}+\tilde{\mathbf{s}}_{t}-\tilde{\mathbf{n}}_{t}\right)+ \\
& -\beta \tilde{\boldsymbol{\psi}}_{t}-\beta \tilde{\boldsymbol{\Omega}}_{t-\tau},
\end{aligned}
$$

where $\gamma_{t}$ is the $(N \times 1)$ vector of average growth rates of GDP per worker, $\mathbb{1}$ is the $(N \times 1)$ vector of ones, $\tilde{\mathbf{y}}_{t-\tau}$ is the $(N \times 1)$ vector of the log of initial GDP per worker in period $[t-\tau, t], \tilde{\boldsymbol{\psi}}_{t}$ is the $(N \times 1)$ vector of the $\log$ of $\psi(\cdot), \tilde{\boldsymbol{G}}_{t}$ is the $(N \times 1)$ vector of the $\log$ of $G(\cdot), \tilde{\mathbf{s}}_{t}$ is the $(N \times 1)$ vector of the $\log$ of investment rates, $\tilde{\mathbf{n}}_{t}$ is the $(N \times 1)$ vector of the $\log$ of employment growth rates augmented by $\delta$ and $\gamma^{A}$ and $\tilde{\Omega}_{t-\tau}$ is the $(N \times 1)$ vector of the log of initial level of technology.

Therefore, the growth rate of GDP per worker of region $i$ in period $[t-\tau, t]$ corresponds to the $i$-th element of $\gamma_{t}$ (remember that $(\mathbf{I}-\theta \mathbf{W}) \mathbb{1}=(1-\theta) \mathbb{1}$ and $\left.\gamma^{A}=\mu /(1-\theta)\right)$ and will be given by:

$$
\begin{aligned}
\gamma_{i t} & \approx \mu+\beta \ln y_{i, t-\tau}-\theta \beta\left[\sum_{j=1}^{N} w_{i j} \ln y_{j, t-\tau}\right]-\beta\left(\frac{\alpha}{1-\alpha}\right)\left[\ln G\left(f_{i t}\right)+\ln s_{i t}-\ln \left(\delta+n_{i t}+\gamma^{A}\right)\right]+ \\
& +\theta \beta\left(\frac{\alpha}{1-\alpha}\right)\left[\sum_{j=1}^{N} w_{i j} \ln G\left(f_{j t}\right)+\sum_{j=1}^{N} w_{i j} \ln s_{j t}-\sum_{j=1}^{N} w_{i j} \ln \left(\delta+n_{j t}+\gamma^{A}\right)\right]+ \\
& -\beta \ln \psi\left(f_{i, t}\right)-\beta \ln \Omega_{i, t-\tau}+\theta\left[\sum_{j=1}^{N} w_{i j} \gamma_{j t}\right] .
\end{aligned}
$$


Substituting Equations (14)-(15) in Equation (26) leads to:

$$
\begin{aligned}
\gamma_{i t} & \approx \mu-\beta \ln \bar{\Omega}-\beta d_{t-\tau}+\beta \ln y_{i, t-\tau}-\beta\left[\eta_{1} f_{i, t}+\eta_{2} f_{i, t}^{2}\right]+ \\
& -\beta\left(\frac{\alpha}{1-\alpha}\right) \ln s_{i t}+\beta\left(\frac{\alpha}{1-\alpha}\right) \ln \left(\delta+n_{i t}+\gamma^{A}\right)-\beta \pi Z_{i, t-\tau}+ \\
& -\theta \beta\left[\sum_{j=1}^{N} w_{i j} \ln y_{j, t-\tau}\right]+\theta \beta\left(\frac{\alpha}{1-\alpha}\right)\left[\sum_{j=1}^{N} w_{i j}\left(\eta_{1}^{G} f_{j, t}+\eta_{2}^{G} f_{j, t}^{2}\right)\right]+ \\
& +\theta \beta\left(\frac{\alpha}{1-\alpha}\right)\left[\sum_{j=1}^{N} w_{i j} \ln s_{j, t}\right]-\theta \beta\left(\frac{\alpha}{1-\alpha}\right)\left[\sum_{j=1}^{N} w_{i j} \ln \left(\delta+n_{j, t}+\gamma^{A}\right)\right]+ \\
& +\theta \sum_{j=1}^{N} w_{i j} \gamma_{j t}
\end{aligned}
$$

where $\eta_{1} \equiv \eta_{1}^{\psi}+\alpha /(1-\alpha) \eta_{1}^{G}$ and $\eta_{2} \equiv \eta_{2}^{\psi}+\alpha /(1-\alpha) \eta_{2}^{G}$. 


\section{List of NUTS2 Regions in the Sample}

\begin{tabular}{|c|c|c|c|c|c|c|c|c|c|}
\hline$\overline{B E 1}$ & Rég. Bruxelles & DK01 & Hovedstaden & FR81 & Languedoc-Roussillon & $\begin{array}{l}\text { NL12 } \\
\end{array}$ & Friesland & $\overline{\text { UKJ1 }}$ & Berkshire, Buckinghamshire \\
\hline BE21 & Antwerpen & DK02 & Sjlland & FR82 & Prov.-Alpes-Côte d'Azur & NL13 & Drenthe & & and Oxfordshire \\
\hline BE22 & Limburg (B) & DK03 & Southern Denmark & FR83 & Corse & NL21 & Overijssel & UKJ2 & Surrey, East, West Sussex \\
\hline BE23 & Oost-Vlaanderen & DK04 & Midtjylland & GR11 & Anatoliki Mak., Thraki & NL22 & Gelderland & UKJ3 & Hampshire, Isle of Wight \\
\hline BE24 & Vlaams Brabant & DK05 & Nordjylland & GR12 & Kentriki Makedonia & NL31 & Utrecht & UKJ4 & Kent \\
\hline $\mathrm{BE} 25$ & West-Vlaanderen & ES11 & Galicia & GR13 & Dytiki Makedonia & NL32 & Noord-Holland & UKK1 & Gloucestershire, Wiltshire \\
\hline BE31 & Brabant Wallon & ES12 & Principado de Asturias & GR14 & Thessalia & NL33 & Zuid-Holland & & and North Somerset \\
\hline BE32 & Hainaut & ES13 & Cantabria & GR21 & Ipeiros & NL34 & Zeeland & UKK2 & Dorset, Somerset \\
\hline BE33 & Liège & ES21 & Pais Vasco & GR22 & Ionia Nisia & NL41 & Noord-Brabant & UKK3 & Cornwall, Isles of Scilly \\
\hline BE34 & Luxembourg (B) & ES22 & Comunidad de Navarra & GR23 & Dytiki Ellada & NL42 & Limburg (NL) & UKK4 & Devon \\
\hline BE35 & Namur & ES23 & La Rioja & GR24 & Sterea Ellada & PT11 & Norte & UKL1 & West Wales, The Valleys \\
\hline DE11 & Stuttgart & ES24 & Aragón & GR25 & Peloponnisos & PT12 & Centro (P) & UKL2 & East Wales \\
\hline DE12 & Karlsruhe & ES3 & Comunidad de Madrid & GR3 & Attiki & PT13 & Lisboa, Vale do Tejo & UKM1 & North Eastern Scotland \\
\hline DE13 & Freiburg & ES41 & Castilla y León & GR41 & Voreio Aigaio & PT14 & Alentejo & UKM2 & Eastern Scotland \\
\hline DE14 & Tübingen & ES42 & Castilla-la Mancha & GR42 & Notio Aigaio & PT15 & Algarve & UKM3 & South Western Scotland \\
\hline DE21 & Oberbayern & ES43 & Extremadura & GR43 & Kriti & PT2 & Açores & UKM4 & Highlands and Islands \\
\hline DE22 & Niederbayern & ES51 & Catalua & IE01 & Border, Mid., Western & PT3 & Madeira & UKN & Northern Ireland \\
\hline DE23 & Oberpfalz & ES52 & Comunidad Valenciana & IE02 & Southern and Eastern & UKC1 & Tees Valley & & \\
\hline DE24 & Oberfranken & ES53 & Islas Baleares & ITC1 & Piemonte & UKC2 & Northumberland & & \\
\hline DE25 & Mittelfranken & ES61 & Andalucia & ITC2 & Valle d'Aosta & UKD1 & Cumbria & & \\
\hline DE26 & Unterfranken & ES62 & Región de Murcia & ITC3 & Liguria & UKD2 & Cheshire & & \\
\hline DE27 & Schwaben & ES64 & Melilla & ITC4 & Lombardia & UKD3 & Greater Manchester & & \\
\hline DE5 & Bremen & FR1 & Ile de France & ITD1 & Bolzano & UKD4 & Lancashire & & \\
\hline DE6 & Hamburg & FR21 & Champagne-Ardenne & ITD2 & Trento & UKD5 & Merseyside & & \\
\hline DE71 & Darmstadt & FR22 & Picardie & ITD3 & Veneto & UKE1 & East Riding, North Lincol. & & \\
\hline DE72 & Gießen & FR23 & Haute-Normandie & ITD4 & Friuli-Venezia Giulia & UKE2 & North Yorkshire & & \\
\hline DE73 & Kassel & FR24 & Centre & ITD5 & Emilia-Romagna & UKE3 & South Yorkshire & & \\
\hline DE91 & Braunschweig & FR25 & Basse-Normandie & ITE1 & Toscana & UKE4 & West Yorkshire & & \\
\hline DE92 & Hannover & FR26 & Bourgogne & ITE2 & Umbria & UKF1 & Derbyshire, Nottingh. & & \\
\hline DE93 & Lüneburg & FR3 & Nord Pas-de-Calais & ITE3 & Marche & UKF2 & Leicestershire, Rutland & & \\
\hline DE94 & Weser-Ems & FR41 & Lorraine & ITE4 & Lazio & & and Northamptonshire & & \\
\hline DEA1 & Düsseldorf & FR42 & Alsace & ITF1 & Abruzzo & UKF3 & Lincolnshire & & \\
\hline DEA2 & Köln & FR43 & Franche-Comté & ITF2 & Molise & UKG1 & Herefordshire, Worcest. & & \\
\hline DEA3 & Münster & FR51 & Pays de la Loire & ITF3 & Campania & & and Warwickshire & & \\
\hline DEA4 & Detmold & FR52 & Bretagne & ITF4 & Puglia & UKG2 & Shropshire and Staffordshire & & \\
\hline DEA5 & Arnsberg & FR53 & Poitou-Charentes & ITF5 & Basilicata & UKG3 & West Midlands & & \\
\hline DEB1 & Koblenz & FR61 & Aquitaine & ITF6 & Calabria & UKH1 & East Anglia & & \\
\hline DEB2 & Trier & FR62 & Midi-Pyrénées & ITG1 & Sicilia & UKH2 & Bedfordshire, Hertford. & & \\
\hline DEB3 & Rheinhessen-Pfalz & FR63 & Limousin & ITG2 & Sardegna & UKH3 & Essex & & \\
\hline DEC & Saarland & FR71 & Rhône-Alpes & $\mathrm{LU}$ & Luxembourg & UKI1 & Inner London & & \\
\hline DEF & Schleswig-Holstein & FR72 & Auvergne & NL11 & Groningen & UKI2 & Outer London & & \\
\hline
\end{tabular}




\section{Descriptive Statistics of Variables}

\begin{tabular}{lccccc}
\hline \hline & GDPpwGr & log.PROD.REL.IN & log.INV.RATE & log.EMP.GR & HC \\
\hline Min & -0.0190 & -1.1462 & -1.9588 & -4.0020 & 2.3399 \\
Median & 0.0110 & 0.0206 & -1.4966 & -3.2879 & 2.7663 \\
Mean & 0.0113 & -0.0221 & -1.4699 & -3.2879 & 2.8304 \\
Max & 0.0476 & 0.5582 & -0.8323 & -2.6474 & 3.2528 \\
St.Dev. & 0.0100 & 0.2564 & 0.2007 & 0.2006 & 0.1944 \\
\hline \hline & $S C F$ & CF & OB1 & OB2 & OtherOB \\
\hline Min & 0.0000 & 0.0000 & 0.0000 & 0.0000 & 0.0000 \\
Median & 0.0011 & 0.0000 & 0.0000 & 0.0001 & 0.0002 \\
Mean & 0.0067 & 0.0009 & 0.0048 & 0.0003 & 0.0007 \\
Max & 0.1041 & 0.0229 & 0.0882 & 0.0023 & 0.0276 \\
St.Dev. & 0.0142 & 0.0025 & 0.0119 & 0.0004 & 0.0018 \\
\hline
\end{tabular}

Table 7: Mean and standard deviation of the variables used in the estimates.

\begin{tabular}{lccccc}
\hline \hline & GDPpwGr & log.PROD.REL.IN & log.INV.RATE & log.EMP.GR & HC \\
\hline GDPpwGr & 1 & 0 & -0.26 & -0.33 & -0.11 \\
log.PROD.REL.IN & 0 & 1 & -0.49 & 0.02 & 0.37 \\
log.INV.RATE & -0.26 & -0.49 & 1 & 0.21 & -0.05 \\
log.EMP.GR & -0.33 & 0.02 & 0.21 & 1 & 0.04 \\
HC & -0.11 & 0.37 & -0.05 & 0.04 & 1 \\
SCF & 0.12 & -0.67 & 0.45 & 0.04 & -0.27 \\
CF & 0.02 & -0.63 & 0.45 & 0.15 & -0.18 \\
OB1 & 0.14 & -0.65 & 0.44 & 0.01 & -0.26 \\
OB2 & -0.22 & 0.09 & -0.06 & -0.01 & 0.06 \\
OtherOB & 0.08 & -0.15 & 0.09 & 0.09 & -0.22 \\
& & & & & OB2 \\
\hline \hline & SCF & CF & 0 OB1 & -0.22 & 0.08 \\
\hline GDPpwGr & 0.12 & 0.02 & 0.14 & 0.09 & -0.15 \\
log.PROD.REL.IN & -0.67 & -0.63 & -0.65 & -0.06 & 0.09 \\
log.INV.RATE & 0.45 & 0.45 & 0.44 & -0.01 & 0.09 \\
log.EMP.GR & 0.04 & 0.15 & 0.01 & 0.06 & -0.22 \\
HC & -0.27 & -0.18 & -0.26 & -0.21 & 0.29 \\
SCF & 1 & 0.86 & 0.98 & -0.16 & 0.19 \\
CF & 0.86 & 1 & 0.8 & -0.26 & 0.15 \\
OB1 & 0.98 & 0.8 & -0.26 & 1 & -0.03 \\
OB2 & -0.21 & -0.16 & 0.15 & -0.03 & 1 \\
OtherOB & 0.29 & 0.19 & & & 0.03 \\
\hline \hline
\end{tabular}

Table 8: Correlations between the variables used in the estimates. 


\section{E Spatial Weights Matrices}

In the empirical analysis we always use a row-standardized spatial weights matrix $\mathbf{W}$ whose element $w_{i j}$ are defined as a (negative) function of the distance between region $i$ and region $j\left(d_{i j}\right)$, that is (see Anselin (2001, pp. 312-313) for a general discussion on spatial weights matrices):

$$
w_{i j}=w_{i j}^{*} / \sum_{j} w_{i j}^{*}
$$

with

$$
w_{i j}^{*}= \begin{cases}0 & \text { if } i=j \\ d_{i j}^{-2} & \text { if } i \neq j .\end{cases}
$$

In particular, in the estimation we use three types of measure of proximity.

1. In the first $d_{i j}$ is defined in geographical terms and is equal to: i) the great circle distance between the centroids of regions $i$ and $j$ (as in Ertur and Koch, 2007, p. 1043), denoted by $d_{i j}^{D}$; or ii) to the fastest travel time between the administrative centres of regions $i$ and $j$ for passengers using roads, denoted by $d_{i j}^{T T}$;

2. in the second $d_{i j}$ is defined in technological terms and is equal to: i) $\sum_{q=1}^{Q}\left(s_{q i}-s_{q j}\right)^{2} / Q$, where $s_{i q}$ is the share of output of sector $q$ in region $i$, and $Q$ is the total number of sectors of economy, denoted by $d_{i j}^{O}$; or ii) $1-0.5 \sum_{q=1}^{Q}\left|p_{q i}-p_{q j}\right|$, where $p_{i q}$ is the share of patents in sector $q$ in region $i$, and $Q$ is the total number of sectors of economy, denoted by $d_{i j}^{P}$;

3. in the third, denoted by $d_{i j}^{G T}, d_{i j}$ is the result of a combination of the previous two types and equal to $\left(\tilde{d}_{i j}^{G}\right)^{\varphi}\left(\tilde{d}_{i j}^{T}\right)^{(1-\varphi)}$, with $\varphi \in[0,1]$ and $\tilde{d}_{i j}^{G}$ (based on either $d_{i j}^{D}$ or $d_{i j}^{T T}$ ) and $\tilde{d}_{i j}^{T}$ (based on either $d_{i j}^{O}$ or $d_{i j}^{P}$ ) representing the standardized geographical and technological proximity respectively (in particular we standardize the log of distance and then take the exponential of the standardized value in order to maintain the non negativity in the measure of proximity).

Following Anderson (2007), we choose $\varphi$ minimizing the AICc of the estimate. 


\section{F Endogeneity Test and Two-Stage Maximum Like- lihood Estimation}

To control for the potential endogeneity of SCF (or the different types of funds) we estimate a spatial panel fixed effect model robust to endogeneity using the following instruments:

- For SCF we use two instruments. The first instrument is the lagged value of SCF, that is the value of SCF in the period 1975-1988 for the unique period composed of Periods I and II and the value of SCF in 1994-1999 for Period III. The second instrument is derived by the three-group method described in Kennedy (2008), in which the instrumental variable takes on values $-1,0$ or 1 if the potentially endogenous variable is respectively in the top, middle or bottom third of its ranking. This instrument is usually utilized when variables are subject to measurement error, as in our case.

- For $\mathrm{SCF}^{2}$ we take as instruments the square of the instruments for SCF as suggested by Wooldridge (2010).

- For W.SCF and W.SCF ${ }^{2}$ we use the spatial lag of the instruments of SCF and $\mathrm{SCF}^{2}$, as well as the instruments derived by the three-group method.

- For each type of funds (CF, OB1, OB2, OtherOB) we always use two instruments as for SCF, i.e. its lagged values and the three-group method; however, given that no break down of funds is present for the period 1975-1988 for funds relative to the unique period composed of Periods I and II, we always used the total amount of funds, while we used the specific lagged value of funds for Period III.

To perform the endogeneity test we use the Control Function method (CFM) (see Wooldridge, 2010, pp. 352-354). The CFM treats endogeneity as an omitted variable problem, where the inclusion of estimated first-stage residuals as a covariate corrects the inconsistency of the regression of the dependent variable on the endogenous explanatory variable. CFM provides consistent estimation of the underlying regression coefficients. 
Therefore, according to CFM we use a two-stage procedure: i) first we regress each endogenous variable on the exogenous variables and the instruments; then, ii) we insert the first-stage residuals in the original regression. Consistently with the two-stage maximum likelihood estimation, in the first-stage regressions we do not consider any spatial dependence and, therefore, we estimate a fixed effect panel linear model. On the contrary, in the second-stage regression we consider the model in Equation (17). In particular, in the second-stage regression we insert all the spatially lagged exogenous and endogenous variables as well as the residuals of the first-stage regressions.

Finally, a Likelihood Ratio (LR) test is conducted to test that the residuals in the second-stage regression are jointly equal to zero. If the null hypothesis can be rejected at the usual level of significance, we estimate the model using a two-stage maximum likelihood estimation (TSML), which consists in: i) a first step where each potentially endogenous variable (i.e. all endogenous variables but the spatially-lagged dependent variable) is regressed on the exogenous variables and the instruments; and ii) a second step where the fitted values of the first-stage regressions are used in the original regression with spatially-lagged dependent variable, which is estimated using standard maximum likelihood. In the first-stage regressions we neglect spatial dependence and use the fixed effect estimator, while in the second-stage regression we estimate the model in Equation (17) via maximum likelihood. The second-step estimation is performed with the package splm in R Core Team (2015) (see Millo and Piras, 2012).

The test of over-identifying restrictions for the validity of instruments is performed following the procedure in Wooldridge (2010, pp. 354-355), which allows to test if the time-demeaned extra instruments are uncorrelated with the idiosyncratic errors in all time periods, without assuming that they are uncorrelated with historical factors contained in the fixed effects. 


\section{G Estimates with Alternative Measures of Geograph- ical and Technological Proximity}

Figure 8 reports the value of AICc for the four types of possible combinations of the two types of proximity $\left(\mathbf{W}^{D O}, \mathbf{W}^{T T O}, \mathbf{W}^{D P}\right.$, and $\left.\mathbf{W}^{T T P}\right)$ for alternative values of $\varphi$. The minimum AICc is reached for $\mathrm{W}^{D O}$ with $\varphi=0.8$.

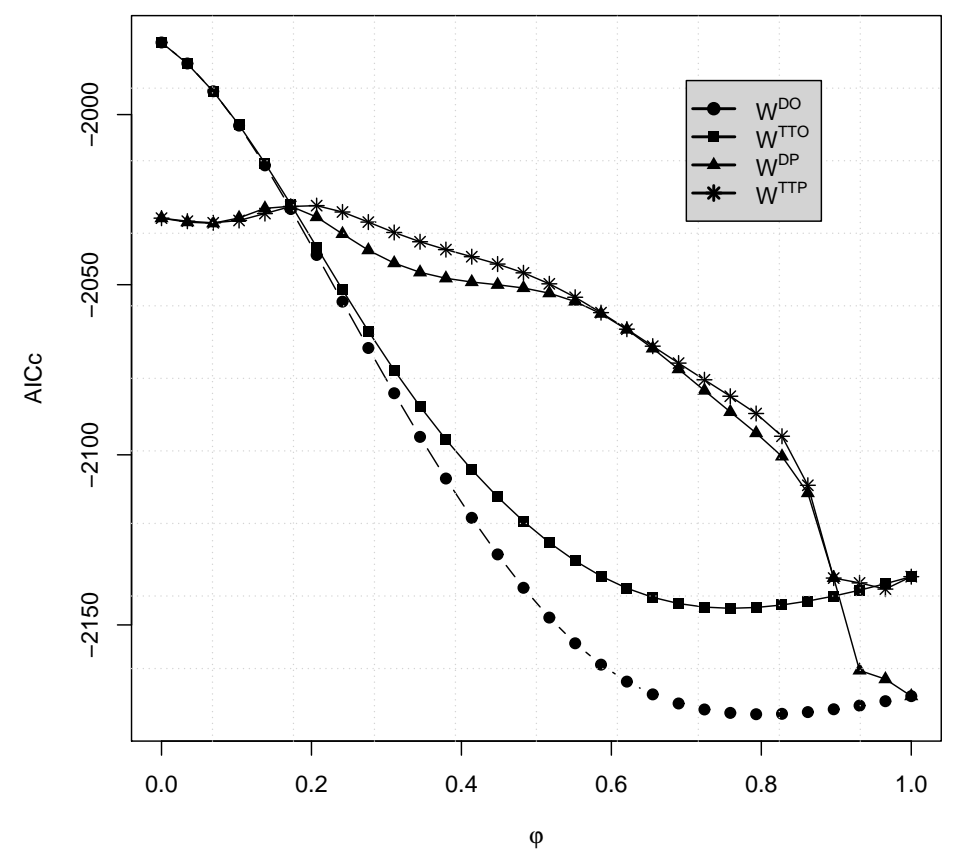

Figure 8: AICc of Model II in Table 4 estimated under different specification of spatial weights matrix W.

Table 9 reports the estimates with $\mathbf{W}^{D}, \mathbf{W}^{T T}, \mathbf{W}^{O}$ and $\mathbf{W}^{P}$ respectively. 


\begin{tabular}{|c|c|c|c|c|c|c|c|c|}
\hline \multirow{3}{*}{$\begin{array}{l}\text { Dependent variable } \\
\text { Spatial Matrix } \\
\text { Model }\end{array}$} & \multicolumn{8}{|c|}{ Average annual growth rate of GDP per worker } \\
\hline & \multicolumn{2}{|c|}{$\mathbf{W}^{D}$} & \multicolumn{2}{|c|}{$\mathbf{W}^{T T}$} & \multicolumn{2}{|c|}{$\mathbf{W}^{O}$} & \multicolumn{2}{|c|}{$\mathbf{W}^{P}$} \\
\hline & $\mathrm{I}$ & II & III & IV & $\mathrm{V}$ & VI & VII & VIII \\
\hline Funds & $\mathrm{SCF}$ & All Obj. & $\mathrm{SCF}$ & All Obj. & $\mathrm{SCF}$ & All Obj. & $\mathrm{SCF}$ & All Obj. \\
\hline REGIONAL FE & YES & YES & YES & YES & YES & YES & YES & YES \\
\hline TIME DUMMIES & YES & YES & YES & YES & YES & YES & YES & YES \\
\hline log.PROD.REL.IN & $\begin{array}{c}-0.067 \\
(0.000)\end{array}$ & $\begin{array}{l}-0.069 \\
(0.000)\end{array}$ & $\begin{array}{l}-0.070 \\
(0.000)\end{array}$ & $\begin{array}{l}-0.070 \\
(0.000)\end{array}$ & $\begin{array}{c}-0.073 \\
(0.000)\end{array}$ & $\begin{array}{c}-0.084 \\
(0.000)\end{array}$ & $\begin{array}{c}-0.064 \\
(0.000)\end{array}$ & $\begin{array}{l}-0.062 \\
(0.000)\end{array}$ \\
\hline log.INV.RATE & $\begin{array}{c}-0.007 \\
(0.010)\end{array}$ & $\begin{array}{l}-0.004 \\
(0.129)\end{array}$ & $\begin{array}{l}-0.005 \\
(0.072)\end{array}$ & $\begin{array}{c}-0.007 \\
(0.034)\end{array}$ & $\begin{array}{c}-0.006 \\
(0.112)\end{array}$ & $\begin{array}{c}0.005 \\
(0.246)\end{array}$ & $\begin{array}{l}-0.011 \\
(0.002)\end{array}$ & $\begin{array}{l}-0.014 \\
(0.000)\end{array}$ \\
\hline log.EMP.GR & $\begin{array}{c}-0.011 \\
(0.000)\end{array}$ & $\begin{array}{c}-0.011 \\
(0.000)\end{array}$ & $\begin{array}{l}-0.012 \\
(0.000)\end{array}$ & $\begin{array}{c}-0.011 \\
(0.000)\end{array}$ & $\begin{array}{c}-0.013 \\
(0.000)\end{array}$ & $\begin{array}{l}-0.013 \\
(0.000)\end{array}$ & $\begin{array}{c}-0.019 \\
(0.000)\end{array}$ & $\begin{array}{l}-0.023 \\
(0.000)\end{array}$ \\
\hline W.log.PROD.REL.IN & $\begin{array}{l}0.041 \\
(0.000)\end{array}$ & $\begin{array}{c}0.028 \\
(0.055)\end{array}$ & $\begin{array}{c}0.055 \\
(0.000)\end{array}$ & $\begin{array}{l}0.031 \\
(0.064)\end{array}$ & $\begin{array}{c}0.039 \\
(0.027)\end{array}$ & $\begin{array}{c}-0.043 \\
(0.089)\end{array}$ & $\begin{array}{c}0.042 \\
(0.004)\end{array}$ & $\begin{array}{c}-0.008 \\
(0.682)\end{array}$ \\
\hline W.log.INV.RATE & $\begin{array}{c}-0.035 \\
(0.000)\end{array}$ & $\begin{array}{c}-0.021 \\
(0.064)\end{array}$ & $\begin{array}{l}-0.030 \\
(0.000)\end{array}$ & $\begin{array}{c}-0.009 \\
(0.586)\end{array}$ & $\begin{array}{c}0.002 \\
(0.889)\end{array}$ & $\begin{array}{c}0.053 \\
(0.002)\end{array}$ & $\begin{array}{c}-0.021 \\
(0.047)\end{array}$ & $\begin{array}{c}0.006 \\
(0.706)\end{array}$ \\
\hline W.log.EMP.GR & $\begin{array}{c}0.013 \\
(0.046)\end{array}$ & $\begin{array}{c}0.015 \\
(0.067)\end{array}$ & $\begin{array}{c}0.016 \\
(0.037)\end{array}$ & $\begin{array}{c}0.018 \\
(0.039)\end{array}$ & $\begin{array}{l}-0.012 \\
(0.182)\end{array}$ & $\begin{array}{c}0.015 \\
(0.147)\end{array}$ & $\begin{array}{c}0.001 \\
(0.871)\end{array}$ & $\begin{array}{c}0.010 \\
(0.262)\end{array}$ \\
\hline $\mathrm{SCF}$ & $\begin{array}{c}0.305 \\
(0.002)\end{array}$ & & $\begin{array}{c}0.239 \\
(0.016)\end{array}$ & & $\begin{array}{c}0.604 \\
(0.000)\end{array}$ & & $\begin{array}{l}1.136 \\
(0.000)\end{array}$ & \\
\hline $\mathrm{SCF}^{2}$ & $\begin{array}{l}-3.004 \\
(0.001)\end{array}$ & & $\begin{array}{l}-2.476 \\
(0.009)\end{array}$ & & $\begin{array}{l}-6.135 \\
(0.000)\end{array}$ & & $\begin{array}{c}-10.200 \\
(0.000)\end{array}$ & \\
\hline W.SCF & $\begin{array}{l}2.848 \\
(0.000)\end{array}$ & & $\begin{array}{l}2.869 \\
(0.000)\end{array}$ & & $\begin{array}{l}1.486 \\
(0.010)\end{array}$ & & $\begin{array}{c}-2.536 \\
(0.000)\end{array}$ & \\
\hline W.SCF ${ }^{2}$ & $\begin{array}{c}-31.686 \\
(0.000)\end{array}$ & & $\begin{array}{c}-30.316 \\
(0.000)\end{array}$ & & $\begin{array}{c}-19.147 \\
(0.007)\end{array}$ & & $\begin{array}{l}17.701 \\
(0.000)\end{array}$ & \\
\hline OB1 & & $\begin{array}{c}0.157 \\
(0.202)\end{array}$ & & $\begin{array}{c}0.161 \\
(0.198)\end{array}$ & & $\begin{array}{c}0.607 \\
(0.001)\end{array}$ & & $\begin{array}{c}0.981 \\
(0.000)\end{array}$ \\
\hline $\mathrm{OB} 1^{2}$ & & $\begin{array}{c}-0.805 \\
(0.537)\end{array}$ & & $\begin{array}{c}-0.898 \\
(0.450)\end{array}$ & & $\begin{array}{l}-4.358 \\
(0.026)\end{array}$ & & $\begin{array}{l}-8.602 \\
(0.000)\end{array}$ \\
\hline OB2 & & $\begin{array}{c}0.024 \\
(0.986)\end{array}$ & & $\begin{array}{l}-0.052 \\
(0.971)\end{array}$ & & $\begin{array}{l}-2.799 \\
(0.130)\end{array}$ & & $\begin{array}{l}-1.402 \\
(0.435)\end{array}$ \\
\hline OtherOB & & $\begin{array}{l}0.015 \\
(0.921)\end{array}$ & & $\begin{array}{c}0.069 \\
(0.658)\end{array}$ & & $\begin{array}{c}0.409 \\
(0.041)\end{array}$ & & $\begin{array}{c}0.465 \\
(0.130)\end{array}$ \\
\hline $\mathrm{CF}$ & & $\begin{array}{l}-0.972 \\
(0.118)\end{array}$ & & $\begin{array}{l}-1.297 \\
(0.046)\end{array}$ & & $\begin{array}{l}-3.909 \\
(0.001)\end{array}$ & & $\begin{array}{l}-1.708 \\
(0.017)\end{array}$ \\
\hline W.OB1 & & $\begin{array}{l}1.127 \\
(0.047)\end{array}$ & & $\begin{array}{c}1.767 \\
(0.010)\end{array}$ & & $\begin{array}{l}4.473 \\
(0.000)\end{array}$ & & $\begin{array}{l}-5.855 \\
(0.000)\end{array}$ \\
\hline $\mathrm{W} . \mathrm{OB} 1^{2}$ & & $\begin{array}{c}-18.988 \\
(0.016)\end{array}$ & & $\begin{array}{c}-24.475 \\
(0.014)\end{array}$ & & $\begin{array}{c}-45.456 \\
(0.000)\end{array}$ & & $\begin{array}{l}55.272 \\
(0.000)\end{array}$ \\
\hline W.OB2 & & $\begin{array}{l}4.657 \\
(0.411)\end{array}$ & & $\begin{array}{c}3.197 \\
(0.660)\end{array}$ & & $\begin{array}{c}-11.627 \\
(0.185)\end{array}$ & & $\begin{array}{l}17.140 \\
(0.122)\end{array}$ \\
\hline W.OtherOB & & $\begin{array}{l}4.345 \\
(0.000)\end{array}$ & & $\begin{array}{l}4.056 \\
(0.000)\end{array}$ & & $\begin{array}{c}-0.899 \\
(0.657)\end{array}$ & & $\begin{array}{l}-4.249 \\
(0.021)\end{array}$ \\
\hline W.CF & & $\begin{array}{l}-0.446 \\
(0.866)\end{array}$ & & $\begin{array}{l}-6.227 \\
(0.113)\end{array}$ & & $\begin{array}{c}-21.542 \\
(0.000)\end{array}$ & & $\begin{array}{c}4.209 \\
(0.002) \\
\end{array}$ \\
\hline$\theta$ & $\begin{array}{c}0.645 \\
(0.000) \\
\end{array}$ & $\begin{array}{c}0.654 \\
(0.000) \\
\end{array}$ & $\begin{array}{c}0.723 \\
(0.000) \\
\end{array}$ & $\begin{array}{c}0.673 \\
(0.000)\end{array}$ & $\begin{array}{c}0.315 \\
(0.001)\end{array}$ & $\begin{array}{c}0.204 \\
(0.040)\end{array}$ & $\begin{array}{c}0.343 \\
(0.000)\end{array}$ & $\begin{array}{c}0.282 \\
(0.001)\end{array}$ \\
\hline $\mathrm{N}$ & 350 & 350 & 350 & 350 & 350 & 350 & 350 & 350 \\
\hline $\mathrm{AICc}$ & -2233.444 & -2171.465 & -2185.631 & -2139.76 & -2003.763 & -1977.948 & -2043.048 & -2041.575 \\
\hline Generalized $\bar{R}^{2}$ & 0.9 & 0.9 & 0.89 & 0.89 & 0.81 & 0.82 & 0.83 & 0.85 \\
\hline LR test of endogeneity & $\begin{array}{l}41.368 \\
(0.000)\end{array}$ & $\begin{array}{l}17.623 \\
(0.062)\end{array}$ & $\begin{array}{l}31.880 \\
(0.000)\end{array}$ & $\begin{array}{l}23.647 \\
(0.009)\end{array}$ & $\begin{array}{l}21.496 \\
(0.000)\end{array}$ & $\begin{array}{l}43.465 \\
(0.000)\end{array}$ & $\begin{array}{l}52.214 \\
(0.000)\end{array}$ & $\begin{array}{l}70.811 \\
(0.000)\end{array}$ \\
\hline Test of over-identifying restrictions & $\begin{array}{c}0.977 \\
(0.404)\end{array}$ & $\begin{array}{c}1.199 \\
(0.303)\end{array}$ & $\begin{array}{c}1.187 \\
(0.315) \\
\end{array}$ & $\begin{array}{c}0.793 \\
(0.594) \\
\end{array}$ & $\begin{array}{c}0.557 \\
(0.643) \\
\end{array}$ & $\begin{array}{c}0.510 \\
(0.827) \\
\end{array}$ & $\begin{array}{c}0.869 \\
(0.457) \\
\end{array}$ & $\begin{array}{c}0.552 \\
(0.794) \\
\end{array}$ \\
\hline
\end{tabular}

Table 9: Estimation of Model (16) under additional specifications of spatial weights matrix and disaggregation of funds. P-values in parenthesis. Funds with two-year lags. Spatial weights matrices are defined in Appendix E. Instrumental variables used in the control of endogeneity of funds (lagged funds and instruments derived by the three-group method described in Kennedy, 2008), the test of endogeneity, and the test of over-identifying restrictions for the validity of instrumental variables are discussed in Appendix F. AICc: Akaike criterion for small samples (see Anderson, 2007). Generalized $\overline{\mathbf{R}}^{2}$ : generalization of $\bar{R}^{2}$ for ML estimates (see Nagelkerke, 1991). 


\section{H First-stage regressions}

\begin{tabular}{|c|c|c|c|c|c|}
\hline & \multicolumn{5}{|c|}{ Dependent variable: } \\
\hline & $\mathrm{CF}$ & OB1 & $\mathrm{OB} 1^{2}$ & OB2 & OtherOB \\
\hline log.PROD.REL.IN & 0.001 & $-0.007^{* * *}$ & $-0.0002^{* * *}$ & $-0.001^{* *}$ & -0.00003 \\
\hline log.INV.RATE & 0.001 & $0.004^{* *}$ & $0.0001^{* * *}$ & -0.0002 & 0.0001 \\
\hline log.EMP.GR & -0.001 & 0.001 & -0.00000 & $0.0002^{*}$ & 0.0002 \\
\hline W.log.PROD.REL.IN & -0.005 & 0.003 & 0.0002 & $0.001^{* *}$ & 0.0002 \\
\hline W.log.INV.RATE & -0.005 & -0.006 & -0.0002 & 0.0004 & -0.001 \\
\hline W.log.EMP.GR & $0.006^{* *}$ & 0.002 & -0.00002 & -0.0004 & -0.0005 \\
\hline lagged.CF & $-0.502^{* * *}$ & $0.731^{* * *}$ & $0.022^{* * *}$ & -0.038 & $0.071^{* * *}$ \\
\hline lagged.OB1 & -0.016 & $-0.778^{* * *}$ & -0.0005 & $-0.016^{* *}$ & 0.005 \\
\hline lagged.OB1 ${ }^{2}$ & -0.059 & $-1.061^{*}$ & $-0.919^{* * *}$ & $0.227^{* * *}$ & 0.044 \\
\hline lagged.OB2 & 0.440 & -0.692 & -0.009 & $-0.323^{* * *}$ & -0.039 \\
\hline lagged.OtherOB & 0.052 & 0.001 & -0.002 & 0.007 & $-0.980^{* * *}$ \\
\hline lagged.W.CF & $0.492^{* * *}$ & $-0.810^{* * *}$ & $-0.019^{* * *}$ & 0.015 & $-0.077^{* * *}$ \\
\hline lagged.W.OB1 & $0.203^{*}$ & $0.653^{* * *}$ & $0.008^{*}$ & -0.019 & -0.013 \\
\hline lagged.W.OB1 ${ }^{2}$ & -3.304 & -2.602 & 0.058 & 0.386 & $0.663^{* *}$ \\
\hline lagged.W.OB2 & 0.760 & -0.119 & 0.002 & $0.505^{* *}$ & 0.050 \\
\hline lagged.W.OtherOB & -0.579 & -0.864 & -0.021 & 0.047 & 0.044 \\
\hline 3.group.CF & 0.002 & $0.005^{* * *}$ & $0.0002^{* * *}$ & -0.0001 & $0.0003^{*}$ \\
\hline 3.group.OB1 & 0.0002 & $0.006^{* * *}$ & $0.0001^{*}$ & -0.0003 & 0.0003 \\
\hline 3.group.OB2 & -0.0001 & -0.0003 & 0.00000 & $0.0003^{* * *}$ & 0.00002 \\
\hline 3.group.OtherOB & 0.00004 & 0.0002 & 0.00001 & -0.00001 & $0.0001^{* * *}$ \\
\hline 3.group.W.CF & 0.0002 & -0.00002 & 0.00000 & 0.0001 & -0.0001 \\
\hline 3.group.W.OB2 & 0.00004 & $-0.001^{* *}$ & $-0.00002^{*}$ & 0.00004 & -0.00005 \\
\hline 3.group.W.OtherOB & -0.00003 & -0.0004 & -0.00001 & -0.00002 & -0.0001 \\
\hline $\mathrm{N}$ & 350 & 350 & 350 & 350 & 350 \\
\hline Generalized $\bar{R}^{2}$ & 0.158 & 0.412 & 0.429 & 0.246 & 0.428 \\
\hline Weak IV F & $4.44^{* * *}$ & $170.22^{* * *}$ & $1536.9^{* * *}$ & $11.30^{* * *}$ & $1161.8^{* * *}$ \\
\hline
\end{tabular}

Table 10: First Stage Regressions of Model II in Table 4. Significance levels: ${ }^{*} \mathrm{p}<0.1 ;{ }^{* *} \mathrm{p}<0.05 ;{ }^{* *} \mathrm{p}<0.01$. Generalized $\overline{\mathbf{R}}^{2}$ : generalization of $\bar{R}^{2}$ for ML estimates (see Nagelkerke, 1991). Weak IV F: test of weakness of instruments. 


\begin{tabular}{|c|c|c|c|c|c|}
\hline & \multicolumn{5}{|c|}{ Dependent variable: } \\
\hline & W.CF & W.OB1 & $\mathrm{W} . \mathrm{OB} 1^{2}$ & W.OB2 & W.OtherOB \\
\hline log.PROD.REL.IN & -0.0003 & $-0.001^{*}$ & -0.00001 & 0.0001 & -0.0001 \\
\hline log.INV.RATE & -0.00003 & 0.001 & 0.00001 & 0.00000 & -0.00000 \\
\hline log.EMP.GR & $0.0004^{* *}$ & 0.0003 & 0.00002 & -0.00002 & 0.00000 \\
\hline W.log.PROD.REL.IN & $-0.002^{* *}$ & $-0.005^{* *}$ & -0.0001 & -0.0002 & -0.00005 \\
\hline W.log.INV.RATE & $0.004^{* * *}$ & $0.009^{* * *}$ & $0.0001^{* *}$ & -0.0001 & 0.0001 \\
\hline W.log.EMP.GR & -0.00002 & -0.001 & -0.0001 & $0.0003^{* *}$ & $-0.0002^{*}$ \\
\hline lagged.CF & 0.030 & $-0.245^{* * *}$ & $-0.009^{* * *}$ & 0.002 & -0.007 \\
\hline lagged.OB1 & $-0.013^{*}$ & $0.082^{* * *}$ & $0.002^{* * *}$ & -0.001 & $0.004^{* * *}$ \\
\hline lagged.OB1 ${ }^{2}$ & 0.099 & -0.108 & 0.006 & 0.002 & -0.011 \\
\hline lagged.OB2 & 0.138 & 0.247 & -0.002 & 0.015 & 0.001 \\
\hline lagged.OtherOB & $-0.022^{*}$ & $0.045^{*}$ & $0.002^{* *}$ & 0.0004 & $0.003^{* *}$ \\
\hline lagged.W.CF & -0.040 & $0.385^{* * *}$ & $0.026^{* * *}$ & -0.003 & $0.023^{* * *}$ \\
\hline lagged.W.OB1 & $0.052^{* *}$ & $-0.538^{* * *}$ & -0.002 & $-0.011^{* *}$ & 0.002 \\
\hline lagged.W.OB ${ }^{1}$ & $-1.193^{* *}$ & 0.434 & $-0.763^{* * *}$ & 0.082 & $0.238^{* * *}$ \\
\hline lagged.W.OB2 & 0.010 & 0.433 & 0.027 & $-0.161^{* * *}$ & 0.031 \\
\hline lagged.W.OtherOB & -0.139 & $-1.120^{* * *}$ & $-0.024^{* * *}$ & $0.035^{*}$ & $-1.011^{* * *}$ \\
\hline 3.group.CF & 0.00000 & 0.0001 & -0.00003 & 0.0001 & 0.00000 \\
\hline 3.group.OB1 & -0.0002 & $0.001^{* *}$ & 0.00001 & 0.00002 & 0.0001 \\
\hline 3.group.OB2 & 0.00003 & 0.0001 & 0.00000 & -0.00001 & 0.00000 \\
\hline 3.group.OtherOB & $-0.0001^{*}$ & -0.0001 & $-0.00000^{*}$ & -0.00001 & -0.00000 \\
\hline 3.group.W.CF & $0.0002^{*}$ & 0.0004 & 0.00000 & -0.00002 & 0.00000 \\
\hline 3.group.W.OB2 & -0.00002 & $-0.0003^{* * *}$ & -0.00000 & $0.0001^{* * *}$ & $-0.00001^{*}$ \\
\hline 3.group.OtherOB & $0.0001^{* *}$ & 0.0001 & 0.00000 & $-0.00002^{*}$ & 0.00001 \\
\hline $\mathrm{N}$ & 350 & 350 & 350 & 350 & 350 \\
\hline Generalized $\bar{R}^{2}$ & 0.124 & 0.415 & 0.429 & 0.243 & 0.428 \\
\hline Weak IV F & $1.65^{* *}$ & $140.80^{* * *}$ & $906.56^{* * *}$ & $10.46^{* * *}$ & $1096.00^{* * *}$ \\
\hline
\end{tabular}

Table 11: First Stage Regressions of Model II in Table 4. Significance levels: ${ }^{*} \mathrm{p}<0.1 ;{ }^{* *} \mathrm{p}<0.05 ;{ }^{* * *} \mathrm{p}<0.01$. Generalized $\overline{\mathbf{R}}^{2}$ : generalization of $\bar{R}^{2}$ for ML estimates (see Nagelkerke, 1991). Weak IV F: test of weakness of instruments. 


\section{Annual Growth Rate of GDP Per Capita}

Table 12 contains the results of the estimation of our model when the dependent variable is the annual growth rate of GDP per capita with $\mathbf{W}=\mathbf{W}^{D O}$ and $\varphi=0.8$ ).

\begin{tabular}{|c|c|c|c|}
\hline Dependent variable & \multirow{2}{*}{\multicolumn{3}{|c|}{$\begin{array}{c}\text { Average annual growth rate of GDP per capita } \\
\mathbf{W}^{D O}(\varphi=0.8)\end{array}$}} \\
\hline Spatial Matrix & 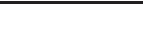 & & \\
\hline Model & $\mathrm{I}$ & II & III \\
\hline Funds & SCF & All Obj. & All Obj. \\
\hline REGIONAL FE & YES & YES & YES \\
\hline TIME DUMMIES & YES & YES & YES \\
\hline log.PROD.REL.IN & $\begin{array}{l}-0.089 \\
(0.000)\end{array}$ & $\begin{array}{l}-0.089 \\
(0.000)\end{array}$ & $\begin{array}{c}-0.086 \\
(0000)\end{array}$ \\
\hline log.INV.RATE & $\begin{array}{l}-0.011 \\
(0.000)\end{array}$ & $\begin{array}{l}-0.009 \\
(0.005)\end{array}$ & $\begin{array}{l}-0.008 \\
(0.006)\end{array}$ \\
\hline log.EMP.GR & $\begin{array}{l}0.030 \\
(0.000)\end{array}$ & $\begin{array}{c}0.029 \\
(0.000)\end{array}$ & $\begin{array}{c}0.029 \\
(0.000)\end{array}$ \\
\hline $\mathrm{HC}$ & & & $\begin{array}{c}0.003 \\
(0.752)\end{array}$ \\
\hline W.log.PROD.REL.IN & $\begin{array}{c}0.102 \\
(0.000)\end{array}$ & $\begin{array}{l}0.097 \\
(0.000)\end{array}$ & $\begin{array}{c}0.114 \\
(0.000)\end{array}$ \\
\hline W.log.INV.RATE & $\begin{array}{l}-0.033 \\
(0.000)\end{array}$ & $\begin{array}{l}-0.037 \\
(0.015)\end{array}$ & $\begin{array}{l}-0.039 \\
(0.011)\end{array}$ \\
\hline W.log.EMP.GR & $\begin{array}{l}-0.029 \\
(0.000)\end{array}$ & $\begin{array}{l}-0.031 \\
(0.001)\end{array}$ & $\begin{array}{l}-0.031 \\
(0.001)\end{array}$ \\
\hline W.HC & & & $\begin{array}{r}0.009 \\
(0.579) \\
\end{array}$ \\
\hline$\overline{\mathrm{SCF}}$ & $\begin{array}{l}0.238 \\
(0.019)\end{array}$ & & \\
\hline $\mathrm{SCF}^{2}$ & $\begin{array}{l}-1.737 \\
(0.070)\end{array}$ & & \\
\hline W.SCF & 2.464 & & \\
\hline W.SCF ${ }^{2}$ & $\begin{array}{l}-32.986 \\
(0.000)\end{array}$ & & \\
\hline OB1 & & $\begin{array}{l}0.118 \\
(0.365)\end{array}$ & $\begin{array}{l}0.129 \\
(0.322)\end{array}$ \\
\hline $\mathrm{OB} 1^{2}$ & & $\begin{array}{l}-0.285 \\
(0.834)\end{array}$ & $\begin{array}{l}-0.468 \\
(0.731)\end{array}$ \\
\hline OB2 & & $\begin{array}{l}-0.407 \\
(0.773)\end{array}$ & $\begin{array}{l}-0.401 \\
(0.776)\end{array}$ \\
\hline OtherOB & & $\begin{array}{l}-0.127 \\
(0.436)\end{array}$ & $\begin{array}{l}-0.023 \\
(0.883)\end{array}$ \\
\hline $\mathrm{CF}$ & & $\begin{array}{l}-0.190 \\
(0.761)\end{array}$ & $\begin{array}{l}-0.121 \\
(0.846)\end{array}$ \\
\hline W.OB1 & & $\begin{array}{l}1.617 \\
(0.007)\end{array}$ & $\begin{array}{l}1.860 \\
(0.003)\end{array}$ \\
\hline W.OB $1^{2}$ & & $\begin{array}{c}-33.260 \\
(0.000)\end{array}$ & $\begin{array}{l}-37.2843 \\
(0.000)\end{array}$ \\
\hline W.OB2 & & $\begin{array}{l}3.648 \\
(0.543)\end{array}$ & $\begin{array}{l}3.092 \\
(0.615)\end{array}$ \\
\hline W.OtherOB & & $\begin{array}{r}4.333 \\
(0.000)\end{array}$ & $\begin{array}{l}3.092 \\
(0.003)\end{array}$ \\
\hline W.CF & & $\begin{array}{l}3.453 \\
(0.320)\end{array}$ & $\begin{array}{l}4.103 \\
(0.244)\end{array}$ \\
\hline $\mathrm{N}$ & 350 & 350 & 350 \\
\hline AICc & -2244.197 & -2174.52 & -2131.17 \\
\hline Generalized $\bar{R}^{2}$ & 0.91 & 0.90 & 0.90 \\
\hline LR test of endogeneity & $\begin{array}{l}45.241 \\
(0.000)\end{array}$ & $\begin{array}{l}12.767 \\
(0.0125)\end{array}$ & $\begin{array}{l}15.141 \\
(0.127)\end{array}$ \\
\hline Test of over-identifying restrictions & $\begin{array}{l}0.944 \\
(0.419)\end{array}$ & $\begin{array}{l}0.226 \\
(0.878)\end{array}$ & $\begin{array}{l}0.559 \\
(0.789)\end{array}$ \\
\hline
\end{tabular}

Table 12: Estimation of Model (16) for GDP per capita under different specification of spatial weights matrix and disaggregation of funds. P-values in parenthesis. Funds with two-year lags. Spatial weights matrices are defined in Appendix E. Instrumental variables used in the control of endogeneity of funds (lagged funds and instruments derived by the three-group method described in Kennedy, 2008), the test of endogeneity, and the test of over-identifying restrictions for the validity of instrumental variables are discussed in Appendix F. AICc: Akaike criterion for small samples (see Anderson, 2007). Generalized $\overline{\mathbf{R}}^{2}$ : generalization of $\bar{R}^{2}$ for ML estimates (see Nagelkerke, 1991). 